\title{
The primary visual system of the rat: A primer of its anatomy
}

\author{
T. E. LeVERE \\ Neuropsychology Laboratory, North Carolina State University, Raleigh, North Carolina 27607
}

\begin{abstract}
The present review is concerned with the anatomy of the primary visual system of the rat. Of principal concern is the pigmented and the albino varieties which are commonly used for behavioral research. Data from other rodents are considered only when necessary to provide a more complete description. While the review is primarily directed toward a description of the anatomy of the eye and retina, the optic nerves and tracts, the lateral geniculate nuclei, the superior colliculi, and the visual neocortex, selected electrophysiological data are also considered to complement the description.
\end{abstract}

For the physiological psychologist, the rat is probably the most popular experimental subject. Its utilization has involved the entire range of empirical procedures from acute electrophysiological investigations to the psychopharmacological study of aging. Increasingly, these researches have utilized experimental paradigms involving visually guided behaviors and their modification by certain treatments. However, and unfortunately, there is no simple straightforward account of the anatomy of the rat's primary visual system against which the psychologist can interpret the results of a particular experiment. This is not to say that the data does not exist, but simply that it is not in one single place. The present report is an attempt to remedy this by summarizing the available descriptions of the anatomy of the rat's visual system.

Because of this intention, it should be pointed out from the onset that the present report is not a theoretical exposé. The report will not address any contemporary anatomical "hot topics" such as regeneration or compensatory neural sprouting. Nor is the present report comparative in nature. Rather, it is simply designed to provide a primer of the anatomy of the rat's primary visual system for those whose major interest is not anatomy but behavior.

Of principle interest is the commonly used laboratory rat of the pigmented (e.g., Long-Evans) and albino (e.g., Sprague-Dawley and Wistar) varieties. In general, it would appear that the hooded and albino varieties are quite similar, with the exception

The present review was conducted as part of Research Grant 5 RO1 NS12459-02 from the National Institutes of Health. Requests for reprints should be directed to T. E. LeVere, Neuropsychology Laboratory, Department of Psychology, North Carolina State University, Raleigh, North Carolina 27607. The author wishes to thank N. Davis and J. Mills for their help in the literature search and D. Miller for her assistance in preparing the report. of certain quantitative differences. For example, the hooded rat appears to have more myelinated fibers in the optic nerve and tract and a thicker visual cortex, while the albino has a somewhat larger eye but fewer crossed fibers. The central termination of retinal fibers and the interaction between the various visual centers is, however, essentially identical in the two animals. Thus, while there may be a certain lack of information concerned specifically with the hooded or the albino rats, the data for the two can, for the most part, be readily transposed to produce a rather complete picture. Where appropriate, we will also consider certain anatomical findings from other rodents and also electrophysiological data when it directly supplements the anatomical picture, as in the quantification of topographical specificity.

The general organization of the present paper will follow the organization of the primary visual system itself. That is, the eye and the retina will be considered first. Next will be a discussion of the optic nerves and tracts and their projection to the lateral geniculate area. Subsequently, the superior colliculi will be considered, and this will be followed by the visual neocortex. The accessory optic system as well as pretectal, lower diencephalic, mesencephalic, and brainstem visual centers will not be considered. As a rule, we will attempt to follow a format which provides: (1) general considerations such as location and gross structural characteristics, (2) afferent and efferent projection patterns, and (3) intrastructural morphology.

\section{THE EYE}

With certain exceptions, notably the size of the lens and cornea, the rat's eye is not dissimilar to other mammalian species, as can be seen from Figure 1. Assuming a mature $(350-\mathrm{g})$ rat and visualizing a plane extending from the external auditory meatus through the attachment of the upper incisors, 


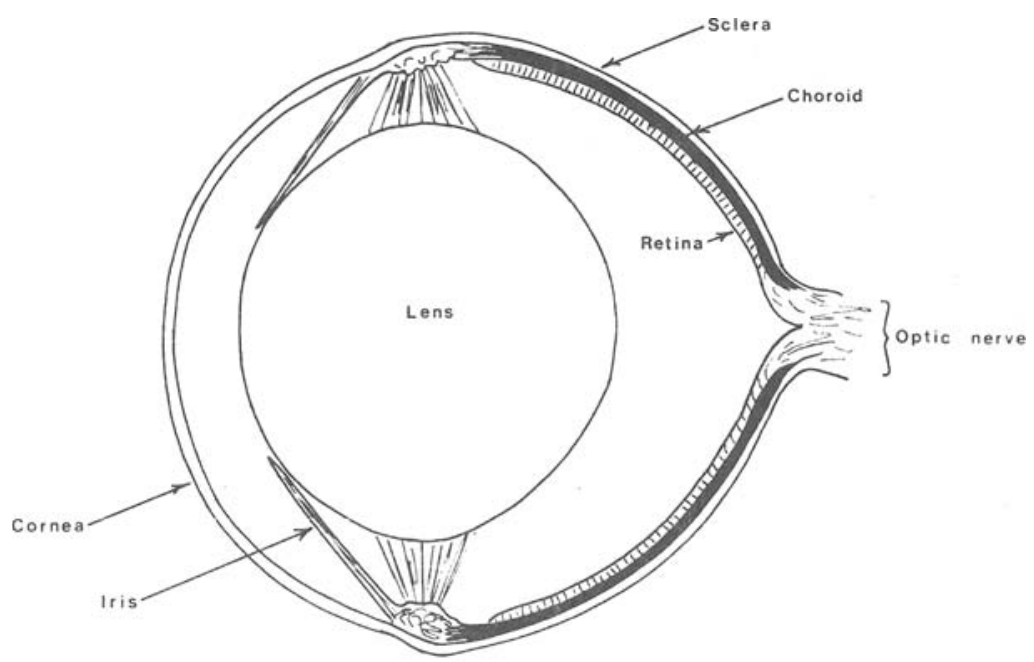

Figure 1. Cross section of the rat's eye. Of importance is the relative size and shape of the lens which is a distinguishing feature. It must be emphasized that this figure, and the majority of those that follow, represent the present author's summary of a variety of information sources and, as such, may involve certain artistic liberties for emphasis. The reader is urged to consult the specific references for actual photographs.

the eyes are located some $10 \mathrm{~mm}$ dorsal to this plane, approximately $18 \mathrm{~mm}$ anterior to the meatus. This location provides a total visual field of approximately $200^{\circ}$ and, assuming a not unlikely convergence of $7^{\circ}$, a binocular overlap of roughly $117^{\circ}$. While the rat is capable of moving its eyes in any direction, the movement is such that the eyes always turn in equal but opposite directions (Lashley, 1932). This, of course, means that convergence is always "off the nose" and requires that the rat turn its head to adequately converge on laterally distinct points in space. This anatomical restriction is most likely what precipitates vicarious trial-and-error behavior (described by many, but named by Muenzinger, 1938) where a rat will rapidly turn its head toward one and then the other stimulus cue during certain phases of two-choice discrimination training. Lashley suggested that this was not some simple behavioral curiosity, but, rather, indicated a foveal-like area on the retinal even though none is present in an anatomical sense.

Quantitatively, the eyeball is quite spherical in shape having an axial diameter of approximately $6.4 \mathrm{~mm}$ and an equatorial diameter of roughly $6.3 \mathrm{~mm}$. The cornea is relatively large and subtends $148^{\circ}$ of the circumference of the eye and entirely fills the opening between the lids of the eye socket. The lens, like the eyeball itself, is very nearly spherical with an axial diameter of $3.9 \mathrm{~mm}$ and an equatorial diameter of $4.5 \mathrm{~mm}$. The lens is supported by a very poorly developed ciliary muscle which is all but absent in some specimens (Lashley, 1932). In contrast to the ciliary muscles, the iris is well developed and shows good reflex movement between diameters of approximately $4 \mathrm{~mm}$ in the relaxed eye to less than $.5 \mathrm{~mm}$ when stimulated with bright light. In fact, a contraction from $2 \mathrm{~mm}$ to $.5 \mathrm{~mm}$ can occur in $.5 \mathrm{sec}$ which is comparable to the human iris.

While early investigators suggested that the rat lacked detailed vision (Waugh, 1910; Yerkes, 1907; and others), Lashley (1932) neatly dispelled this notion by some very elegant and simple observations using a freshly exorcised eye from an albino rat. In the albino, the sclera is nearly clear and for up to approximately $30 \mathrm{~min}$ it is possible to use the eye as an optical system, with the sclera being analogous to the ground glass of a photographic camera. Lashley's tests indicated that images were typically best formed at between 7.5 and $8 \mathrm{~cm}$ and with a flair typical only to Lashley, commented: "With one albino eye, giving the sharpest focus at $6 \mathrm{~cm}$, with the iris fully dilated, the image of the text print of this JOURNAL was clearly legible when the page was $15 \mathrm{~mm}$ from the cornea. With the same eye the image of a human hand 2 meters distant was easily recognizable and the outlines of buildings and the movements of automobiles two blocks away could be traced." However, it should be noted that Lashley's observations were based on images formed on the sclera, which is somewhat behind the actual receptors so that his estimates are somewhat in error (Adams $\&$ Forrester, 1968). Nonetheless, the rat clearly possesses an optical system capable of detailed vision and certainly is not hypermetropic as sugested by Vincent (1912).

\section{THE RETINA}

\section{General Considerations}

The retina, which contains the actual receptive elements, is a layered structure of alternating somata 
and the interaction of their processes. The number of layers varies, depending upon who is describing the structure, but usually is considered to be between 7 and 10 . In size, the rat's retina subtends $175^{\circ}$ of the circumference of the eye. The optic disk, where the optic nerve is formed, is approximately $6.5 \%$ of the diameter of the retina, and thus yields a blind spot corresponding to $11^{\circ}$. Blood vessels radiate equally from the optic disk, and there is no indication of a foveal depression.

\section{Afferent-Efferent Projections}

The single efferent projection of the eye is, of course, the optic nerve which exits the retina at the optic disk. The optic nerve courses centrally with most of the fibers decussating at the optic chiasma, after which they are called the optic tract. With respect to the neural centers presently under consideration, these fibers innervate the lateral geniculate nucleus and the superior colliculus. Details of this projection will be considered more fully when the optic nerve and tract, the lateral geniculate nucleus, and the superior colliculus are reviewed.

While there may be general agreement upon the efferent projection of the eye, a similar concensus is not found relative to a possible centrifugal projection. Even though certain anatomical descriptions of the retina using Golgi staining techniques have described axon-like fiber processes of possible central origin (Polyak, 1941), no central nucleus, such as the isthmo-optic nucleus of the chick, has been described for the rat. Thus, at least for the present, it is perhaps best to consider the receptor system of the eye as simply an output system.

\section{Intrastructural Morphology \\ Cellular Morphology}

The retina contains three distinct neural elements and a single structural element, the Müller cell. The neural elements are the: (1) receptors, (2) inner neurons, and (3) efferent neurons. The receptor elements are the typical mammalian rod cell and possibly, although there is some dispute, the cone cell. The inner neurons are the horizontal cells, of which there is one type; the bipolar cells, of which there are two types; and the amacrine cells, of which there are also two types. The efferent (projection) neurons are the ganglion cells, of which one or more types are described, depending, in part, upon the histological preparation of the material under study. These elements may be summarized as follows:

(A) Receptors
(1) Rods
(2) Cones (?)

(B) Inner neurons

(1) Horizontal type

(2) Bipolar type (a) Type I bipolar

(b) Type II bipolar

(3) Amacrine type

(a) Diffuse amacrine

(b) Widefield amacrine

(C) Efferent neurons

(1) Ganglion type
(a) Diffuse ganglion
(b) Giant ganglion
(c) Stratified ganglion cells
1. Unistratified ganglion
2. Bistratified ganglion

(d) Displaced ganglion

In organizational terms, these elements are grouped into 3 distinct nuclear layers (outer, inner, and ganglion) which alternate with 2 plexiform layers (outer and inner). It should be noted that here, and throughout the remaining description of the retina, outer refers to a location toward the sclera. While there is apparently little dispute concerning the alternating nuclear and plexiform layers of the retina, there is some disagreement concerning the details of their organization. That is, 3 distinguishable nuclear layers and 2 plexiform layers yield a total of 6 layers if the outer segments of the receptor elements are included as a separate layer (Dubin, 1970). However, Lashley (1932) described 8 layers while Polyak (1941) described 10 layers with no less than 16 different subdivisions. For the purposes of the present discussion, and largely as a matter of convenience, we will assume a somewhat intermediate position and distinguish 7 layers: (1) the pigmented cell layer, (2) the receptor segment layer, (3) the outer nuclear layer, (4) the outer plexiform layer, (5) the inner nuclear layer, (6) the inner plexiform layer, and (7) the ganglion cell layer. The composition of these layers is summarized below and diagramed in Figure 3.

(A) Pigmented cell layer

(B) Receptor segment layer

(1) Outer segments of receptor cells

(2) Inner segments of receptor cells

(C) Outer nuclear layer

(1) Receptor cell somata

(D) Outer plexiform layer

(1) Synapses between
(a) Receptor cell bases
(b) Horizontal cell processes
(c) Bipolar cell processes

(E) Inner nuclear layer

(1) Horizontal cell somata

(2) Bipolar cell somata

(3) Amacrine cell somata

(4) Displaced ganglion cell somata

(F) Inner plexiform layer

(1) Synapses between

(a) Bipolar cell processes

(b) Amacrine cell processes 
(c) Ganglion cell processes

(G) Inner nuclear layer

(1) Ganglion cell somata (except displaced ganglion cell)

In general terms, there is a gross vertical and horizontal organization within these retinal layers. The vertical organization involves the receptor units which synapse with bipolar cells which, in turn, synapse with ganglion neurons. The horizontal organization, on the other hand, is at two levels and involves the horizontal cells at the outer plexiform layer and the amacrine cells at the inner plexiform layer. At the outer plexiform layer, the horizontal cells provide a linkage between individual receptor units, while at the inner plexiform layer, the amacrine cells provide a similar function with respect to bipolar cells and ganglion neurons. With this organization in mind, we will now consider the individual neural elements of the retina and then attempt to further specify certain aspects of their synaptic interaction.

Receptor cells. A preliminary and old, and as yet unsettled, question concerning the receptors of the rat's retina is whether or not there are only rod-type receptor cells or both rod-type and cone-type receptor cells. Lashley (1932) cites several authors who describe cone-type processes (Krause, 1895; Menner, 1929cited in Lashley, 1932; Schultz, 1866), but he, himself, was unable to confirm these observations. Detwilar (1943) agreed with Lashley's conclusions. However, Walls (1934) reported what he considered to be clearly distinguishable cone-type receptors in his preparations, which he argued were better than those of Lashley. Yet, it is difficult, in even the best prepared material, to define cone and rod on anatomical criteria restricted to the outer segment of the receptor.

However, there is another anatomical feature which distinguishes rods and cones, and this is their synaptic apparatus in the outer plexiform layer. Recent observations, while not specifically addressing the question of duplicity, have often suggested, in passing, the existence of both rod-like synaptic bases, that is, the rod spherical, and cone-like synaptic bases, that is, the cone pedicle. Notwithstanding this, however, there are no anatomical studies specifically addressing differences in the synaptic bases of the receptor units of the rat's retina, so the suggestion falls short of being totally convincing. And even should these descriptions be available, it would still remain necessary to functionally demonstrate the anatomical potential, and here the results are also quite equivocal.

From a functional point of view, the well-known Purkinje shift has been a major phenomenon used to confirm retinal duplicity. While it is relatively easy to electrophysiologically demonstrate this in certain mammalian eyes, this is not the case with respect to the rat. For example, Graham and Riggs (1935) and Granit (1947) reported the complete lack of a Purkinje shift in their investigations. On the other hand, Doyt and Echte (1961) as well as Muntz (1967) have both found what appears to be a small but clearly detectable shift toward the red region of the visible spectrum under light adaptive testing. But even should it be possible to clearly demonstrate a Purkinje shift in support of certain anatomical specifications, one is still faced with the further problem of behavioral utilization. And here the data are all but entirely lacking. Thus, like so many other questions concerned with structure-function relationships, considerable further investigatory effort is required.

Whether or not the rat retina contains both rods and cones, and the question is of some import if the rat's visual system occupies the transitional position awarded it by Polyak (1957), it would appear that the receptor, be it rod or cone, is composed of four highly distinguishable parts. These parts are similar to those of other mammals and include: (1) the outer receptor segment, (2) the inner receptor segment, (3) the somata, and (4) the synaptic base. Also similar to other mammals, the orientation of the receptor unit is such that it is pointed toward the sclera. As diagramed in Figure 2, the outer segment is the

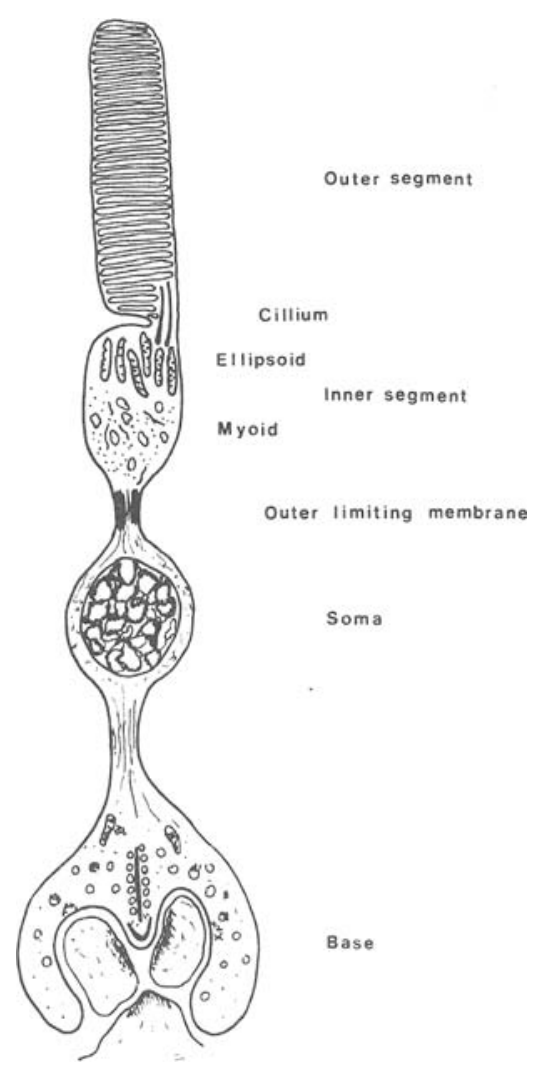

Figure 2. Diagram of the rat's rod receptor. Horizontal cell processes are represented by the structures within the lateral invaginations of the synaptic base. The intermediate process within the base is from a bipolar cell. The synaptic ribbon within the base is represented by the thick vertical line with its accumulation of synaptic vesicles. The rod arciform density is the crescent-shaped structure directly below the ribbon. Sclera is toward the top. 
actual biological transducer, and is composed of a stack of densely packed flattened sacks. These sacks, as described by Sjöstrand (1953) for the guinea pig, are double-membraned disks which, under the magnification provided by the electron microscope, appear continuous around their entire edge. Moreover, the disks essentially define the diameter of the outer segment, since the only other readily discernible component is a thin membrane which encapsulates the stack. In terms of actual dimensions, the diameter of the disks is approximately $2 \mu$; the double membranes are separated by a 70-80- $\AA$-high compartment, and each is approximately $30 \AA$ thick. The distance separating each double membrane disk is approximately $100-200 \AA$ depending upon the adequacy of the fixation and embedding procedures. While each of the disks is a separate entity, they are connected by a series of stalks running along a narrow groove, or incision, which, while discernible, does not disrupt the continuity of the double-membrane disk itself.

The outer segment of the rod is connected to the inner segment by a bundle of 16-18 thin fibrils surrounded by a membrane which, at least in primates, is considered to be a true cilium (Noback \& Laemle, 1970). These fibrils, which connect the otherwise separated outer and inner segments, proceed down the apical half of the inner segment and are in intimate contact with mitochondria of this area. The inner segment itself can be subdivided into an outer ellipsoid region, distinguished by a dense aggregation of elongated mitochondria, and an inner myoid region, characterized by numerous Golgi complexes, scattered vesicular components, and considerable quantities of free and membrane-bound ribosomes.

Before leaving the description of the outer and inner segment of the receptor unit, it is of some importance to summarize a process suggesting that the outer segment is something other than a static transducer of electromagnetic energy. The process was described by Young (1967), who injected labeled amino acids into rats and analyzed its retinal dispersion at different periods after the injection. The results indicated that shortly after the injection $(1 / 2 \mathrm{~h})$, a radioautographic reaction appeared over the inner rod segment. Over a period of an additional 9 days, this reaction formed a distinct band at the base of the outer segment and progressed toward the apex of the outer segment, where it finally disappeared. These observations indicate a process where the membrane disks at the apex of the outer segment are undergoing continual removal, with a concomitant development of membrane disks at the base of the receptor element. The presence of lysosomes, acid phosphates, and other indicators of intracellular digestion in the pigmented cell layer would tend to support this notion. Moreover, the renewal rate is accelerated when the rat's eyes are stimulated with more intense illumination. Thus, like some other receptor units, notably taste receptors, the receptors of the retina are not in any way static but appear to undergo a continuous process of rejuvenation of, at least, the biological transducer portion of the unit.

Returning to the anatomy of the receptor, the outer and inner segments are continuous with the soma of the receptor unit via a thin fibrous process. The soma itself lies in the outer nuclear layer of the retina and is separated from the more sclerad outer and inner segments by a structure somewhat inappropriately labeled the outer limiting membrane. The inappropriateness of the label stems from the fact that the outer limiting membrane is not a membrane at all, but rather an accumulation of dense material in the form of a ring just below the base of the inner segment. Under the light microscope, these dense rings appear as a membrane, but in reality each ring is associated only with the individual receptor it surrounds and is not continuous with any other ring.

The final portion of the receptor, the synaptic base, lies in the outer plexiform layer, where it contacts the processes of bipolar cells and horizontal cells. Following the elegant descriptions of De Roberts and Franchi (1956), Gray and Pease (1971), Ladman (1958), and Leure-duPree (1974), the present report will concentrate upon the synaptic base of the rod receptor. This concentration is not necessarily a denial of cone receptors within the rat's retina, but simply a concession to available data. In general terms, the rod synaptic base, that is the rod spherical, is one of the largest synapses in the central nervous system and may be characterized as a bulbar ending containing a bilobular invagination resembling two juxtaposed footballs.

Ladman (1958) has further described the rod spherical as containing a single large mitochondria located above the bilobular invagination, although other authors have not specifically confirmed this observation. Other elements within the cytoplasm of the spherical are granular and innerplasmic reticulum and, of course, synaptic vesicles. Within the separation between the upper portions of the bilobular invagination are two structures. One of these is a rather large, flat structure termed the rod-synaptic lamella by Ladman. Others have simply considered this structure as a synaptic ribbon (Gray \& Pease, 1971; Leure-duPree, 1974) to correspond to similar synaptic structures within the axon terminals of certain bipolar cells. The other synaptic structure is the rod arciform density which is interposed between the synaptic ribbon and the presynaptic membrane of the spherical itself. In intimate contact with the synaptic ribbon are numerous synaptic vesicles lined along its extent, which suggests that the synaptic ribbon, and additionally the arciform density, may serve a function similar to the dense projections of more conventional synapses. We shall return to this point in our 
discussion of the synaptic interrelations of the retina.

Horizontal cells. The horizontal cells form the scleral boundary of the inner nuclear layer, and only one type has been described (Leure-duPree, 1974). This cell, which is typically considered anaxonic, yields a minimum of 15 dendritic processes from its scleral surface. The processes radiate to spread over a distance of approximately 20-30 $\mu$, with, at least for the rat, all being directed toward the outer plexiform layer. Thus, the horizontal cells provide a lateral integration within the retina at the level of the outer plexiform layer.

Amacrine cells. The amacrine cells form the vitreal boundary of the inner nuclear layer and are generally classified into two major groups, the diffuse amacrine cells and the widefield amacrine cells. The somata of the diffuse amacrine cells rest just below the somata of the bipolar cells. Its processes extend from the vitreal surface and have a tufted or brush-like appearance as they descend to the inner plexiform layer (see Figure 3). The range of these processes is generally somewhat restricted compared to the widefield amacrine cell and extends between 25 and $60 \mu$. The widefield amacrine cell has a similarly located somata and may be described as either a triangular widefield amacrine cell or a pear-shaped widefield amacrine cell (see Figure 3). The triangle-shaped widefield amacrine cells have their processes arising from the lateral surface of the somata, from where they spread horizontally. In contradistinction, the pear-shaped widefield amacrine cells usually display only a single vitreal process which descends into the inner plexiform layer before it divides and proceeds horizontally. The processes of both the triangular and pear-shaped widefield amacrine cells principaliy remain within a single plane within the plexiform layer and cover a relatively large area, extending over a range of approximately $40-60 \mu$. These major types of amacrine cells are thus the inner plexiform layer counterpart of the horizontal cells previously described.

Bipolar cells. The bipolar innerneurons have their somata between those of the horizontal cells and the amacrine cells and may be categorized into two general types: Type I bipolar cells and Type II bipolar cells (see Figure 3). The Type I bipolar cell is the most frequent and has a dendritic process which divides many times en route to the outer plexiform layer to contact up to 10 different receptor units. The axon of this bipolar cell descends to the inner plexiform layer, where it then expands into several large terminal areas with the successive swellings extending nearly to the ganglion cell layer. The Type II bipolar cell, in comparison, has fewer dendritic processes and usually does not branch until reaching the outer plexiform layer, where it may show only one bifurcation. The axon of the Type II bipolar cell descends only to the sclerad portion of the inner plexiform layer. However, once at this location, the axon branches considerably. Notwithstanding this branching, the axons of the Type II bipolar cell typically remain in a single plane and none have been observed to descend to the ganglion cell layer. If one excludes Cajal's infrequently described and little understood descending horizontal cell, the bipolar cell provides the retina with all of its vertical integration between the receptor units and the projection neurons (the ganglion cells). Moreover, assuming the possibility that the rat's retina contains both rods and cones, it has been suggested (Leure-duPree, 1974) that the Type I bipolar cells synapse with rod-type receptors and the Type II bipolar cells synapse with cone-type receptors. However, it must again be cautioned that there is little hard anatomical evidence concerning the cone pedicle and its distinction from the rod spherical in rat.

Ganglion cells. There are four general types of ganglion cells. These general types are the displaced ganglion cells within the inner nuclear layer and the diffuse ganglion cells, giant ganglion cells, and stratified ganglion cells within the ganglion cell layer. It is also possible to dichotomize the stratified ganglion cells into a unistratified ganglion cell group and a bistratified ganglion cell group.

The displaced ganglion cell is not readily discernible in Golgi prepared material, but is easily observed following the central injection of horseradish peroxidase (Bunt, Lund, \& Lund, 1974). The problem is, of course, that, while the existence of the displaced ganglion cell may be established with horseradish peroxidase, this technique does not provide much information concerning cellular morphology. Thus, while it is clear that the displaced ganglion cell exists, that it has relatively large perikarya (approximately $20 \mu$ ), and that it is preferentially located in the central portion of the retina, little else is certain.

Turning to the ganglion cells within the ganglion cell layer, the diffuse ganglion cell has a soma of roughly $12-21 \mu$. The dendrites of this cell are relatively thin and beaded with occasional spines; they ramify at all levels of the inner plexiform layer. The giant ganglion cells are similar to those described by Polyak for the primate retina and have somata greater than $20 \mu$. The dendrites of the giant ganglion cell are relatively thick, smooth, and free of dendritic spines; they extend throughout the inner plexiform layer. The unistratified ganglion cells have somata of approximately $12-19 \mu$ in diameter. The dendritic branches of the unistratified ganglion cell, of which there are one or two apical types, have numerous spines and are restricted to a single plane in the inner plexiform layer. The bistratified ganglion cell, on the other hand, has a somewhat larger soma (17-22 $\mu)$ and several relatively thick apical dendrites which 
exhibit only occasional spines. The dendrites appear to ramify in two planes, which are restricted to either the outer one-third or the middle one-third of the inner plexiform layer.

\section{Synaptic Morphology}

Synaptic interaction within the retina is confined to two areas or layers, the outer plexiform layer and the inner plexiform layer (Figure 3). The outer plexiform layer, as previously noted, contains the bases of the receptor units as well as the dendritic processes of horizontal cells and bipolar cells. The principal synaptic arrangement in this layer is the triad, so named because of the sharing of one presynaptic element by three postsynaptic elements. The presynaptic element of the triad is the synaptic base of the receptor unit with its bilobular invagination. The postsynaptic elements of the triad are dendritic processes of horizontal cells which project one process to each lobular invagination and a bipolar dendritic process located directly below the synaptic ribbon between the two horizontal processes (see Figure 2). Postsynaptic membrane specializations are confined to those areas proximal to the cleft between the bilobular invagination, where the synaptic ribbon and its halo of synaptic vesicles are located.

With regard to the contents of the presynaptic base of the receptor unit, Gray and Pease (1971) have described three principal elements, namely, plain synaptic vesicles, complex or coated synaptic vesicles, and shell fragments. Gray and Pease have suggested a process where components of expelled synaptic transmitter substance are recovered through pinocytosis within the zone of the presynaptic membrane that lines the bilobular invaginations. It is their suggestion that the complex or coated vesicles are formed at this point when transmitter materials are budded-off into the interior of the presynaptic base. Within the coated synaptic vesicle, the complete transmitter substance is formed, and then the coating breaks off and the plain synaptic vesicle is transferred to contribute to the halo of vesicles along the synaptic ribbon. The arciform density in this arrangement has, then, two functions. First, it serves to anchor the synaptic ribbon to the appropriate location at the presynaptic cleft. Second, because of certain shelf-like structures between the arciform density and the synaptic ribbon, the arciform density may serve as a guide to direct the synaptic vesicles from the synaptic ribbon to the appropriate location on the presynaptic membrane for their release into the synaptic gutter. Following these propositions, but principally the recovery of synaptic transmitter substances, Gray and Pease offer an alternative to the suggestion of Eccles and Jaeger (1958) that the lobular shape of the synaptic base functions to increase the efficiency of the synapse by restricting

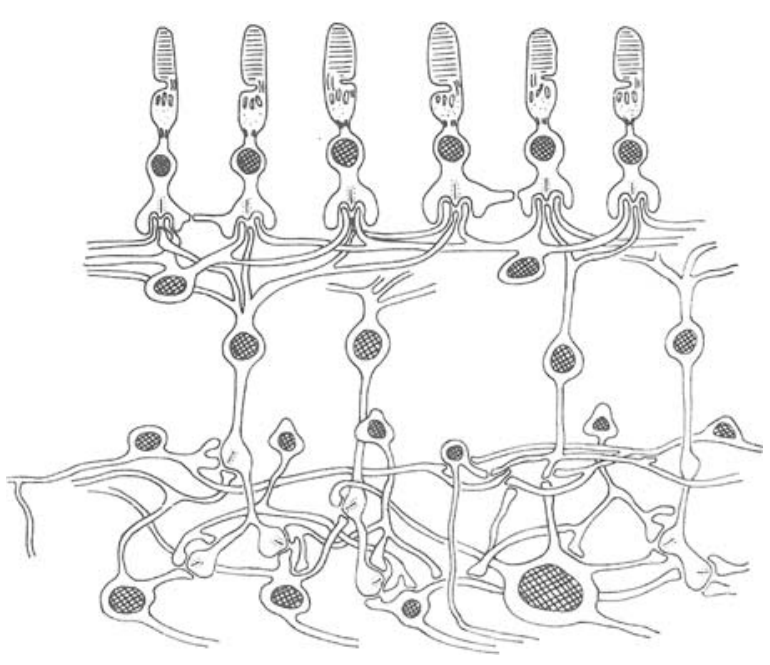

Figure 3. Schematic representation of the rat's retina. Of note is the indication of the displaced ganglion cell (third from right in the inner nuclear layer) and the triad synaptic arrangement associated with Type I bipolar cells in the inner plexiform layer.

the rate of diffusion of transmitter substance. Gray and Pease, on the other hand, argue that the restriction of diffusion of transmitter substance is not to make the synapse more efficient per se but, rather, to facilitate the rapid uptake of the transmitter substance by the presynaptic membrane. Whether or not this is a valid description of the functional significance of the synaptic base of retinal receptor units remains to be seen; however, the proposition has some appeal since the synapse of the retinal photoreceptor is probably one of the busiest in the mammalian nervous system.

In addition to the triad synaptic arrangement of the outer plexiform layer, an additional type of synapse, the tight junction, has been described (Leure-duPree, 1974). The tight junction is a "synapticbase-to-synaptic-base" synapse with synaptic densities typical of the Tray Type II synapses but usually no complement of synaptic vesicles. Detection of the tight junction is based principally on the fact that, typically, the receptor elements are separated by the nonneural Müller cell, except in certain instances where a process from one synaptic base makes contact with a process from another synaptic base. If LeureduPree's suggestion that synaptic bases without synaptic ribbons are characteristic of cones in the rat retina, then it is possible to define an arrangement where a cone-type receptor base extends horizontally to form a tight junction with several surrounding rod-type bases. This sort of interaction is, of course, common to the primate retina and, should it be valid to define cone pedicles on the basis of their lack of synaptic ribbons, is an important finding relative to the synaptic morphology of the rat's retina. However, it must be remembered that the definition of a cone pedicle as being a synaptic base without a synaptic ribbon is somewhat atypical. 
The second synaptic area of the retina is the inner plexiform layer. While the synaptic arrangements of the inner plexiform layer may or may not be more complex than those of the outer plexiform layer, they certainly show a greater variety. The elements forming the synaptic arrangements are the axon processes of bipolar cells and the processes of amacrine cells, with both the bipolar processes and amacrine processes being both pre- and postsynaptic. The third type of synaptic elements in the outer plexiform layer are the dendritic processes of ganglion cells which are exclusively postsynaptic. The synaptic arrangements that have been described (Dubin, 1970; Leure-dupree, 1974; Sosula \& Glow, 1970) are: (1) conventional synapses, (2) dyads, (3) reciprocal synapses, and (4) serial synapses. Tight junctions such as those of the outer plexiform layer have not been described.

The conventional synapses are similar to those in the central nervous system and need not further be discussed. The dyad is a synaptic arrangement so named because two postsynaptic processes share a single presynaptic element. The presynaptic element of the dyad is the bipolar cell and is characterized by a synaptic ribbon with its concomitant halo of synaptic vesicles-the only inner plexiform process so endowed. The postsynaptic elements may either be a ganglion dendritic process and an amacrine cell process or, alternatively, two amacrine cell processes. The amacrine cell processes may form reciprocal synapses back to the bipolar process of the dyad, with the bipolar cell being the postsynaptic element. The final synaptic arrangement is the serial synapse. This typically involves an amacrine cell presynaptic to a second amacrine cell, which is, in turn, presynaptic to a third, and so on, involving up to four or five amacrine cell processes.

Numerically, the incidence of amacrine synapses to bipolar synapses is, according to Sosula and Glow (1970), approximately 8:1, with the highest incidence of amacrine synapses in the middle third of the inner plexiform layer. This is a somewhat lower ratio than that set by Lashley (1932) of $36: 14: 1$ with respect to receptor:bipolar:ganglion cells; however, Lashley did not distinguish between amacrine and bipolar cells in the inner plexiform layer. As in the outer plexiform layer, and for that matter the entire retina, the major glial component is the Müller cell. Finally, there is as yet no adequate correlation between the variously described ganglion cells, bipolar cells, and amacrine cells which may be observed in Golgi prepared material and the synaptic relationships described above. It should, however, be remembered that the Type I bipolar cells extend throughout the inner plexiform layer to the ganglion cell layer, while the Type II bipolar cells are typically restricted to the sclerad portion of the inner plexi- form layer. This and various distributions of the two types of amacrine cells and the five types of ganglion cells then allow some educated speculations which we leave to the reader's enjoyment.

\section{THE OPTIC NERVE AND TRACT}

As previously described, the axon processes from the ganglion cells course within the retina toward the optic disk, where they gather and exit the eyeball, forming the optic nerve. The optic nerve from each eyeball then moves toward the brain, with one converging upon the other until both blend together at the optic chiasma. At this point, roughly $90 \%$ of the axon processes cross while $10 \%$ remain ipsilateral. Relative to the brain areas presently under consideration, the optic tracts, as the fibers are called when central to the chiasma, then travel in a dorsocaudal direction between the internal capsules medial to their path and the amygdala and caudate-putamen complexes of the overlying and lateral cerebral hemispheres. Following this route, the optic tracts pass under the fimbria of the hippocampus and flow over the lateral border of the lateral geniculate nuclei of the thalamus, where most, if not all, yield collateral fibers. These collateral fibers then, in turn, either terminate within the lateral portions of the lateral geniculate nuclei or pass through to terminate in pretectal areas. The main branch of the optic tract, after passing over the lateral boundary of the lateral geniculate nucleus forms the brachium of the the superior colliculus and finally terminates in the optical layer of this structure.

According to Lashley (1934), there is little topographic organization within the optic nerve and optic chiasma. The optic tracts are, however, somewhat more organized with the uncrossed fibers, tending to remain chiefly within the inner half of the bundle. The crossed fibers, on the other hand, are organized such that those from ganglion cells in the peripheral retina are concentrated in the lower portions of the optic tract, while fibers originating from ganglion cells near the optic disk tend to be distributed throughout the height of the optic tract. Moreover, ganglion cells located in the temporal retinal quadrants tend to be grouped in the inner half of the tract, while those from the nasal retinal quadrants tend to be grouped in the outer half of the optic tract. Lashley suggested that this organization corresponded rather closely to the ultimate destination of the fibers in the lateral geniculate nucleus, although certain, more recent, evidence suggests that Lashley's description of the lateral geniculate organization was not itself correct in all details.

Using the light microscope, it has been estimated (Bruesch \& Arey, 1942) that there are approximately 80,000 visual fibers in the optic nerve and tract 
of the pigmented rat and approximately 75,000 fibers in the optic nerve and tract of the albino rat. The majority of these fibers are myelinated, with the pigmented rat showing approximately $99 \%$ myelination and the albino rat showing some $20 \%$ less myelination. Under the electron microscope, however, these estimates have been revised upward somewhat, at least for the optic nerve and tract of the albino rat (Forrester \& Peters, 1967). That is, it would seem that there are approximately 117,000 visual fibers in the optic nerve and tracts and that all of these fibers are myelinated. Forrester and Peters suggest that the difference between their figures and the earlier estimates using light microscopy is due to the fact that the electron microscope is able to detect very fine fibers and the occurrence of very thin myelination. It must be noted, however, that even the electron microscope shows a very small number of smalldiameter fibers $(.18 \%)$ as being unmyelinated. Forrester and Peters suggest that this small number of unmyelinated fibers simply reflects the fortuitous sectioning of the fibers at the nodes of Ranvier. The extremely small number of detected unmyelinated fibers lends some credence to this suggestion, except that there is the nagging question of why only fine fibers should be sectioned at the nodes of Ranvier. Thus, while it seems certain that most of at least the larger-diameter fibers are myelinated, it would seem prudent to hold open the possibility that there are a small number of small-diameter fibers which are unmyelinated.

The presence of myelination indicates that the action potentials of the optic nerves and tracts may be conducted at relatively fast speeds. Recent electrophysiological evidence tends not only to support this, but also to suggest that there are three, if not four, groups of fibers conducting at different speeds (Sefton, 1968; Sefton \& Swinburn, 1964; Sumitomo, Ide, Iwama, \& Arikuni, 1969). The data, though not entirely consistent, suggests that there are groups of fibers conducting at speeds of 19.2, 11.9, 5.2, and $3.2 \mathrm{~m} / \mathrm{sec}$. Moreover, this electrophysiological evidence clearly supports the notion that those fibers innervating the lateral geniculate nucleus also innervate the superior colliculus, as suggested by the early anatomical judgments of Cajal (1911), Lashley (1934), and Tsang (1937). However, it must be noted that there is evidence that the contrary may not be true, i.e., all fibers entering the superior colliculus need not necessarily also innervate the lateral geniculate nucleus. While this latter point was made quite early by Lashley (1934), it is also quite true that should these fibers exist, they are very small in number. It would, of course, be of unquestionable importance to determine whether or not the fibers exclusively associated with the superior colliculus may also have some restricted retinotopic organization. Similarly,

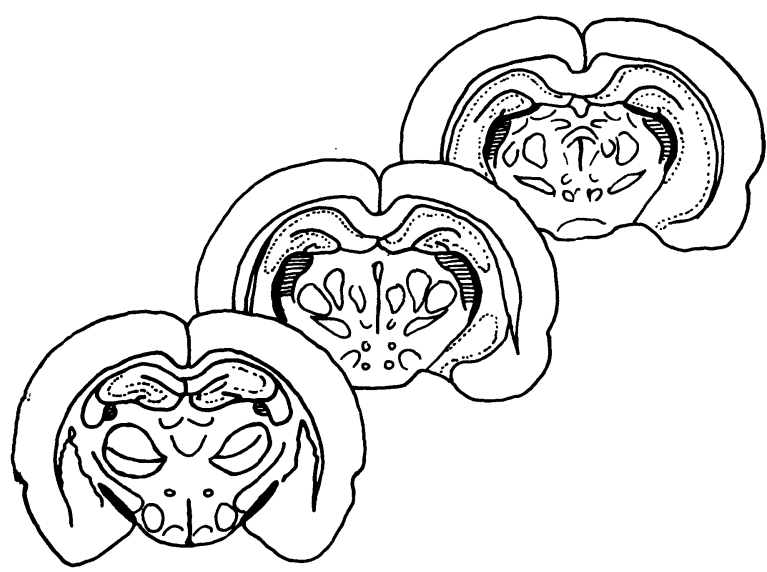

Figure 4. Three coronal sections of the rat brain indicating the general location and size of the dorsal and ventral portions of the lateral geniculate nucleus (horizontal lines) and the optic tract (heavy black areas).

it would also be of great interest to determine whether or not there is a retinotopic distribution of those fibers having different conducting speeds. For example, one might speculate, on the one hand, that central vision should be afforded the fastest conducting fibers, but it is also possible to speculate, on the other hand, that stimuli in the peripheral retina demanding attention shifts might command those fibers having the fastest conducting speed as well as being those exclusively related to the superior colliculus. Clearly these are questions whose answers would afford much to understanding what the rat's eye tells the rat's brain.

\section{THE LATERAL GENICULATE NUCLEUS}

\section{General Considerations}

The first nuclei encountered by the axons of the retinal ganglion cells are the lateral geniculate nuclei of the thalamus. The visual system is somewhat unique in this respect, since it is the only sensory system where a thalamic nucleus is the first nuclear relay subsequent to the receptor apparatus. This distinction excludes, of course, the olfactory system, which does not project to the thalamus. The lateral geniculate nucleus (LGN) is subdivided into a dorsal portion (LGNd) and a ventral portion (LGNv) separated by an internuclear plexus. Both of these subdivisions receive retinal and cortical input, however, only the dorsal portion projects to visual neocortex.

The general location of the lateral geniculate nucleus is shown by the horizontal striations in the series of frontal sections presented in Figure 4. The optic tract in this figure is indicated by the solid black area which sweeps up and over the lateral surface of the nucleus. Considering both the dorsal and ventral portions, the nucleus is somewhat kidney- 
shaped in its frontal plane and tapers in both the anterior and posterior directions, although somewhat more so anteriorly. The LGN is bordered on its dorsolateral side by the hippocampus and the fimbria of the hippocampus and medially by a number of thalamic nuclei, namely from dorsal to ventral, the posterior lateral thalamic nucleus, the lateral thalamic nucleus, the ventral dorsomedial thalamic nucleus, and the ventral thalamic nucleus. Ventrally the LGN blends into the zona incerta. In terms of our mature $350-\mathrm{g}$ rat, and at a level defined by the convergence of the dorsal and ventral portions of the hippocampus, the LGNd measures $.6 \mathrm{~mm}$ dorsoventrally and $1.1 \mathrm{~mm}$ mediolaterally while extending anteriorly $1.5 \mathrm{~mm}$ and posteriorly some $.5 \mathrm{~mm}$. The horizontal and sagittal dimensions of the LGNv are, respectively, $.4 \mathrm{~mm}$ and $1.1 \mathrm{~mm}$, with the anterior-posterior extent just smaller than that of the LGNd.

From Nissl-prepared material, the LGNd shows its largest cells within its middle one-third (anteriorposterior dimension), with cells more lateral (proximal to the optic tract) tending to be somewhat smaller. On the basis of Nissl staining, there is no indication of any lamination. The ventral portion of the lateral geniculate nucleus may be sagittally divided into a lateral and medial portion, with the lateral portion showing the largest cells and these tending to accumulate in the posterior area of the nucleus. As with the dorsal portion, Nissl stain again provides no indication of any lamination within the nucleus.

\section{Afferent}

\section{Afferent-Efferent Relationships}

A better appreciation of the complexity of the rat lateral geniculate nucleus may be gained by studying the degeneration pattern following enucleation. Typically, the procedure involves the removal of one eye, following which the experimental subject is allowed to survive for some 5-7 days. After this period of time, the animal is sacrificed and the brain sectioned and stained for degenerating fibers and terminals. In general, there is fairly good agreement that the lateral geniculate nucleus has both contralateral and ipsilateral input to both its dorsal and ventral portions. However, as noted previously, the contralateral input is much more extensive and there would appear to be some quantitative difference between pigmented rats and albino rats as well as the intermediate hooded variety. Moreover, the specific organizational pattern of the contralateral and ipsilateral retinal input is somewhat dependent upon the particular histological procedure which is used to detect the degenerating fibers and terminals.

Figure 5 presents a summary of this degeneration data (Cunningham \& Lund, 1971; Goodman, Bogdasarian, \& Horel, 1973; Goodman \& Horel, 1966; Hayhow, Sefton, \& Webb, 1962). That is, the horizontal lines represent contralateral terminal degeneration and the vertical lines represent ipsilateral terminal degeneration, with line thickness related to the quantity of degeneration. Considering first the LGNd, it can be seen that while the contralateral degeneration is certainly more extensive than the ipsilateral degeneration, it is far from uniform. Rather, there is a maximal contralateral degeneration near the lateral border of the nucleus subjacent to the optic tract. Moreover, in the dorsomedial portion of the nucleus, there is a zone where there is significantly less contralateral degeneration, and here there appears to be at least a rudimentary beginning of lamination. The ipsilateral pattern to LGNd corresponds quite nicely to the minimal contralateral degeneration and appears to maximize at the junction of the middle and posterior one-thirds of this area of the nucleus.

Turning to the ventral portion of the lateral geniculate nucleus, there was some early question as to whether or not there was actually terminal degeneration as well as degeneration of the fibers of passage (Lashley, 1934; Tsang, 1937; Nauta \& Stratten, 1947).

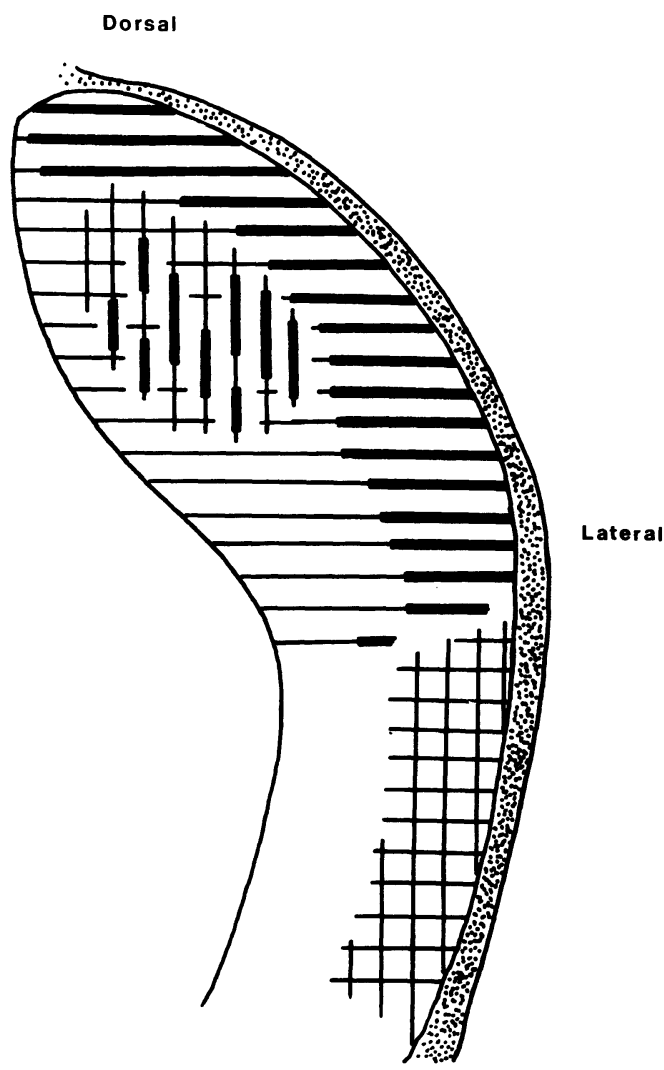

Figure 5. Coronal section through the dorsal and ventral portions of the lateral geniculate nucleus. The figure indicates the terminal degeneration following contralateral (horizontal lines) and ipsilateral (vertical lines) enucleation. The thickness of the lines represents the relative amount of degeneration. The optic tract is indicated by the stippled area to the right. 


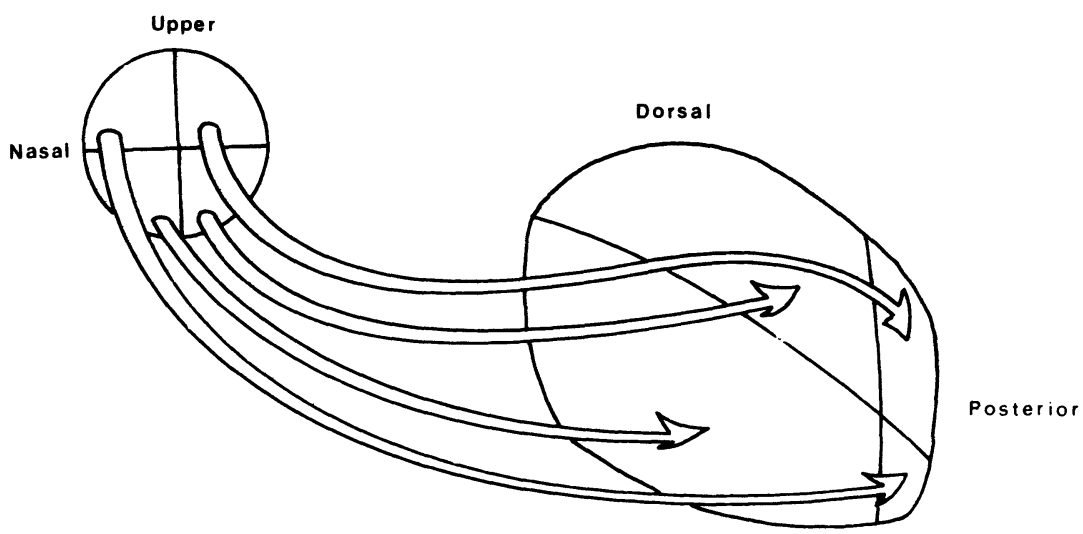

Figure 6. Topographical distribution of retinal fibers over the dorsal portion of the lateral geniculate nucleus. The figure is arranged such that the observer faces the lateral surface of the left LGNd and "looks through" the rat's brain to the back surface of the right retina.

However, the weight of contemporary evidence favors the proposition that retinal axons not only pass through this portion of the nucleus, but also terminate here, with the termination being confined to the lateral subdivision. In contradistinction to the dorsal portion of the nucleus, however, the degenerating terminals appear to be evenly distributed save for some sparseness of the contralateral projection near the inner nucleus fiberplexes and somewhat heavier ipsilateral degeneration in the posterior twothirds of the LGNv. Notwithstanding this, there appears to be rather complete overlap between contralateral and ipsilateral terminals within the LGNv.

The above description is a generalization, and, to be sure, there are certain discrepancies in detail between the various researchers. While these differences within a given strain of rat and histological procedure are small enough to be dismissed on technical grounds, the differences which exist between strains of rats are compelling and worthy of note. For example, Giolli and Creel (1974) noted rather large differences between the intense phenotype (black rat), the hooded rat, and the albino rat, particularly with regard to the ipsilateral projection to the dorsal portion of the lateral geniculate nucleus. The black rat showed a much larger ipsilateral projection than the hooded rat, which in turn presented an ipsilateral projection larger than that observed in the albino rat. Moreover, this ipsilateral projection was organized in only one lamina in the black rat, two to three lamina in the hooded rat, and three separate and distinct lamina in the albino rat. It must, however, be quickly added that these observations should be tempered with the qualification that the variability within the hooded variety was, in fact, quite great and much more than that in the black rat, which in turn was slightly more than that in the albino rat. It should be emphasized, though, that the noted differences, while large, really repre- sent quantitative distinctions and do not suggest any qualitatively unique characteristics.

Finally, it is perhaps best to caution that not only strain differences, but also histological techniques may provide distinct pictures of the organization of the retinal input to the lateral geniculate nucleus. For example, Cunningham and Lund (1971) demonstrated that, while the neurofibrillar method yielded considerably less contralateral degeneration within the LGNd, it did demonstrate a rather clear indication of lamination compared to the picture presented by the Fink-Heimer procedure. In contradistinction to the contralateral projection, both of the histological techniques showed similar patterns of degeneration with respect to the ipsilateral projection. While it is possible to relate the differences regarding the contralateral projection to certain aspects of synaptic morphology, i.e., encapsulation, why there is such a similarity of the two techniques with respect to the ipsilateral projection is somewhat worrisome, unless, of course, one is willing to accept the possibility that the ipsilateral axon terminals participate only in encapsulated synaptic arrangements.

To further refine the termination pattern, it is possible to study retinal input to the lateral geniculate nucleus by the degeneration pattern following restricted retinal lesions (Lund, Lund, \& Wise, 1974) as compared to enucleation. Dividing the retina into quadrants it is possible to relate these quadrants to the dorsolateral and posterior surfaces of the contralateral dorsolateral geniculate nucleus in a retinotopic fashion. Remembering that we are considering the retina, as opposed to the visual field, the upper half of the retina projects to the most posterior area of the LGNd while the lower half of the retina projects somewhat more extensively over the remaining surface (Figure 6). The temporal half of the retina projects to the dorsomedial surface of LGNd, while the nasal quadrants project to the more ventrolateral 


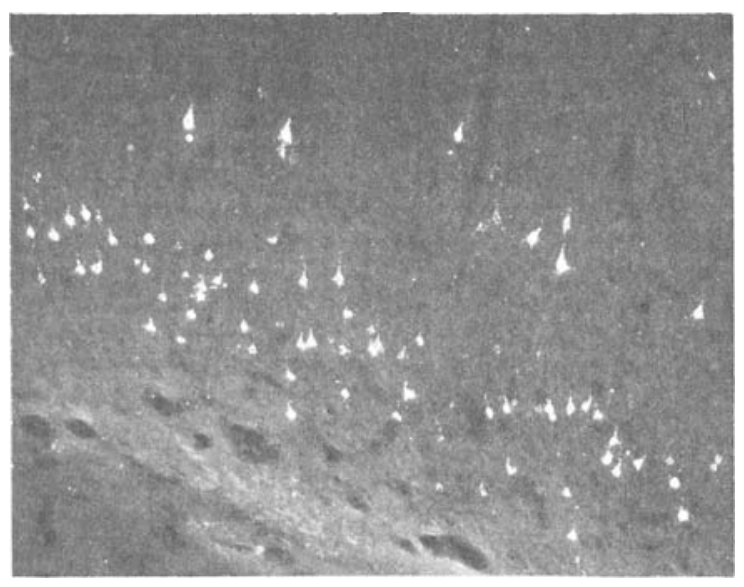

Figure 7. Occurrence of horseradish peroxidase uptake by both the large equilateral pyramidal cells in layer $V$ and the smaller pyramidal cells in layer VI of area 17 following an injection restricted to the dorsal portion of the lateral geniculate nucleus. Dark-field illumination. Cortical surface is upward. Lateral is to the right. Magnification $\times 10$.

surface. From the surface, the various retinal points form lines of projection which run inward and anteriorly within the nucleus itself.

These anatomical data agree quite well with the results obtained using electrophysiological techniques to map the lateral geniculate nucleus (Montero, Brugge, \& Beitel, 1968). Moreover, the electrophysiological data nicely picture the internuclear projection lines described by Lund et al. (1974). As with the anatomical data, the electrophysiological data indicate that the lines of projection from specific retinal areas are oriented obliquely to the surface along lines extending from a dorsolateral position in the posterior region to a ventromedial position in the anterior region of the nucleus. Additionally, the electrophysiological data provide a general confirmation of the existence and location of the ipsilateral projection as previously described, although Montero et al. were unable to detect the existence of the lamination suggested by Hayhow et al. Finally, the electrophysiological data suggest the existence of some considerable degree of overlap of certain receptive fields within the LGNd. The location of these fields corresponds closely to Lashley's presumed area of central vision, which he defined on the basis of increased numbers of ganglion cells. However, the electrophysiological data do indicate that the area is somewhat more extensive than Lashley had originally considered it to be. With respect to the LGNv, it is perhaps worthwhile to note that the retinal projections to this portion of the nucleus also indicate some retinotopic organization, although it is grosser than that of the dorsal portion.

Thus, summarizing the retinal projection to the lateral geniculate nucleus, it would appear that the rat shows both crossed and uncrossed projections to both the LGNd and LGNv, although the crossed projection is obviously more extensive. Moreover, the dorsal portion of the lateral geniculate nucleus appears to exhibit the elementary beginnings of the laminar organization shown in higher animals, although it is most incomplete and presents considerable overlap. Whether or not one wishes to enthusiastically espouse the existence of true lamination or at least the beginnings of true lamination, the fact remains that the nucleus is quite a bit more complex than the early Nissl material suggested. The possibility of laminae, or at least the elementary beginnings of laminae, would appear, if nothing else, to further confirm Polyak's (1957) classification of the rat's visual system as an intermediate visual system.

A second major afferent input to the lateral geniculate area is from visual neocortex (Goodman \& Horel, 1966; Montero \& Guillery, 1968; Nauta \& Bucher, 1954). The axons of this projection arise from medium and small pyramidal cells of layers 5 and 6 of area 17 (Figure 7; LeVere \& Davis, unpublished observations). The route of this corticofugal projection essentially follows that of the optic radiations and flows over the dorsal surface of the corpus callosum, moving in a general anterior direction to curve under the fimbria of the hippocampus (Figure 8; LeVere \& Davis, unpublished observations). At this point, the fibers mingle with those in the dorsal portion of the internal capsule and the superior thalamic radiation and then turn dorsally to enter the lateral geniculate nucleus from a somewhat ventromedial approach. While both the dorsal and ventral portions of the lateral geniculate nucleus are reciprocants of this corticofugal input, it is generally conceded that the LGNd receives considerably less than

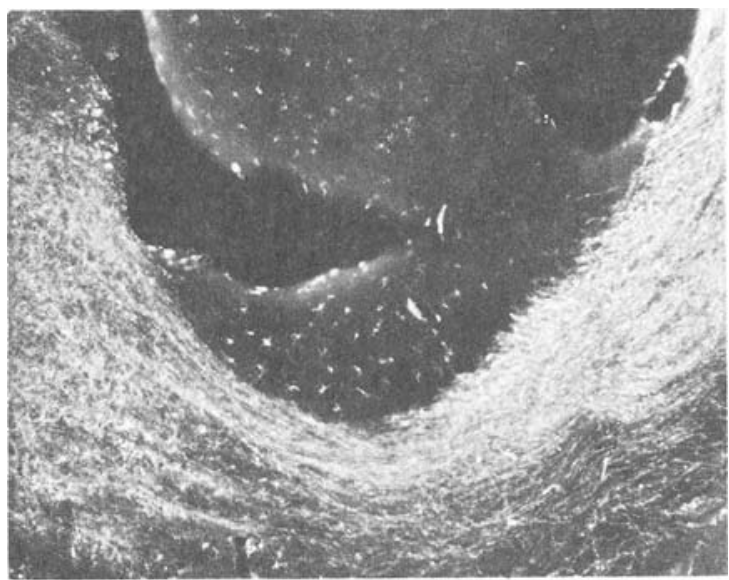

Figure 8. Optic radiations as they exit the lateral geniculate nucleus, as indicated by horseradish peroxidase labeled axons. The fiber processes can be seen to pass under and around the fimbria of the hippocampus. The section is some 4 to $4.2 \mathrm{~mm}$ anterior to the inner aural line. Dark-field illumination. Cortical surface is upward. Lateral is to the right. Magnification $\times 10$. 
the LGNv. In terms of distribution, the corticofugal fibers to the dorsal portion of the lateral geniculate nucleus tend to concentrate principally in the medial and dorsal aspects of the LGNd, while those projecting to the ventral portion of the nucleus have a somewhat wider distribution and spread throughout its medial subdivision.

\section{Efferent}

The major efferent projection of the LGNd is, of course, the optic radiation. The projection is comprised of the axons of the projection neurons, which exit rostrolaterally and travel in a somewhat ventral direction to loop around the stria terminalis in front of the hippocampal flexure (see Figure 8). From this point, the fibers travel from the caudal limb of the internal capsule and then through the caudate nucleus, where they eventually turn laterally and enter the white matter below the neocortex anterior to and lateral to the striate area. In a fashion similar to that of the corticofugal fibers described above, these fibers then travel up over the dorsal surface of the corpus callosum as they move caudally to innvervate their target region of the neocortex, area 17 (but see Footnote 1).

The efferent projection of the LGNv nucleus is divided into two dorsomedial projections and three ventromedial projections (Ribak \& Peters, 1975; Swanson, Cowan, \& Jones, 1974). The dorsomedial projections go to the superior colliculus, where they terminate mainly in the medial third of the optical layer, the ipsilateral pretectal area via the superior thalamic radiation, and the contralateral pretectal area via the posterior commissure. The ventromedial projections involve the pons and ipsilateral zona incerta as well as a projection to the contralateral LGNv via Meynert's commissure in addition to both ipsilateral and contralateral brainstem areas. It

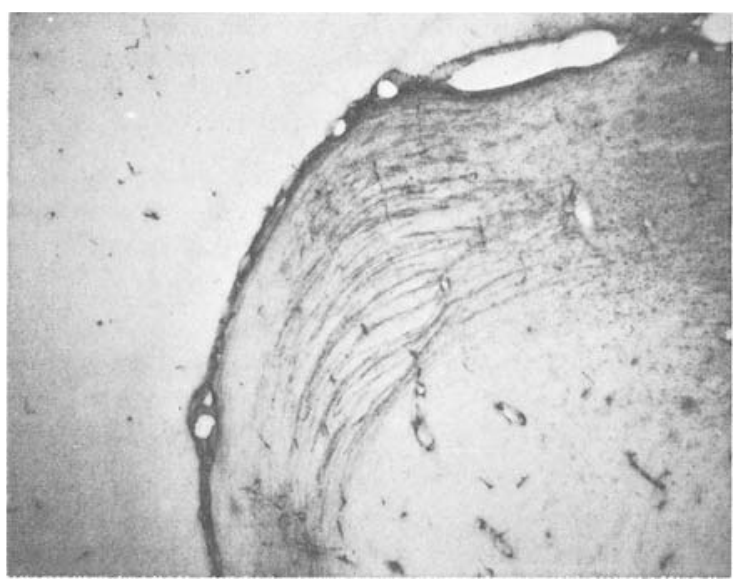

Figure 9. Coronal section through midregion of dorsal lateral geniculate nucleus, showing the transverse fiber system as these are labeled by the uptake of horseradish peroxidase. Cortical surface is upward. Lateral is to the left. Magnification, $\times 10$. should be noted that the termination of the efferent projections of $\mathrm{LGNv}$, as defined by radioactive labeling, appear to precisely overlap the retinofugal projection in every instance save for the superior colliculus. In the superior colliculus, the LGNv efferents are distributed mainly in the deeper layers overlapping the projection from the striate and prestriate area of neocortex, while the retinofugal fibers are mainly more superficial. It is, however, important to keep in mind that, with the autoradiographic technique, it is often difficult to determine whether the radioactive labeling is the result of the termination of fibers or fibers of passage. Thus, the complete picture may require confirmation by other histological techniques, such as the retrograde transportation of horseradish peroxidase as well as the detection of degenerating fibers following discrete neural lesions.

\section{Intrastructural Morphology}

Before specifically discussing the cellular and synaptic morphology of the lateral geniculate nucleus, it is necessary to describe two prominent fiber systems within at least the dorsal portion of the lateral geniculate nucleus. These are the transverse fiber system and the longitudinal fiber system (Montero \& Guillery, 1968). The transverse fiber system runs across the nucleus in a coronal plane from a ventrolateral position to the dorsomedial boundary of the nucleus (see Figure 9; LeVere \& Davis, unpublished observations). The fibers themselves are collected into discrete bundles of both coarse and fine caliber $(2$ to $.5 \mu)$. The longitudinal fiber system has similar size fibers, although these are not arranged into discrete bundles. However, it is possible to discern an oblique orientation of these fibers as they travel through the nucleus from the posterior lateral area to the anterior medial tip. In the posterior one-third of the nucleus, the fibers are relatively sparse, but they increase in density as the longitudinal system courses anteriorally, which is not terribly surprising, since the system exits the rostral end of the LGNd. It should be noted, if it is not already apparent, that the longitudinal system parallels the projection of single retinal points within the dorsal portion of the lateral geniculate nucleus. While the fibers of both the transverse and longitudinal systems cross each other throughout the nucleus, there is not any clear and precise indication of their communication save for the observation of very fine fibers turning from the transverse system to run parallel to the longitudinal system. However, because of the fineness of these fibers, it is impossible to trace them for any great distance.

With respect to the just described afferent and efferent projections of the LGNd, the transverse 
fiber system is associated with both retinofugal and corticofugal fiber processes that both terminate and pass through the LGNd. The retinal processes are typically those within the dorsolateral portions of the transverse fiber system, as indicated by the fact that there is little degeneration in the ventromedial portion following enucleation. Contrariwise, the corticofugal processes are predominantly confined to the ventromedial portions of this transverse fiber system, as shown by degeneration patterns following restricted visual neocortical lesions. The longitudinal fiber system, on the other hand, is principally associated with the efferent geniculocortical fibers, as indicated by late indirect Wallerian degeneration. Thus, the dorsal portion of the lateral geniculate body receives both retinal and cortical fibers of termination and passage and, additionally, projects to the visual neocortex. And the afferent fibers are principally associated with the transverse fiber system, while the efferent fibers are principally associated with the longitudinal fiber system. Finally, it is perhaps worthwhile to note that the transverse fiber system is also most probably associated with afferents from sites originating in brain centers outside the discussion of the present review. These are principally brainstem areas, and the interested reader is referred to the excellent observations of Graybiel (1974).

\section{Cellular Morphology}

Contemporary descriptions of cellular morphology have concentrated on the dorsal portion of this thalamic nucleus. Here, as with most of the thalamic nuclei, both projection neurons, that is, those whose axons extend beyond boundaries of the nucleus, and intrinsic neurons, that is, those whose processes remain within the boundaries of the nucleus, have been described. The projection neurons, which appear to be distributed throughout the LGNd (Kriebel, 1975), have been variously labeled as P-cells (Lund \& Cunningham, 1972), TSR-cells for thalamostriate relay (Rafols \& Valverde, 1973), Class A and Class A-radiate cells (Grossman, Lieberman, \& Webster, 1973), and Typ I and Type II cells (Kriebel, 1975). A more general label for these projection cells, and the one presently adopted without any severe claim to validity, is TCR to identify the cells as thalamocortical relay cells. The present choice of TCR is simply a concession to generality with regard to the thalamic efferents that have been described for other nuclei.

Generally, the size of the somata of the TCR cells, independent of their label, is between 15 and $30 \mu$, with a mean of 20-25 $\mu$. The dendritic processes branch extensively to yield four to eight primary dendrities, with each having second-order and thirdorder branches. While the primary dendrites appear to be quite smooth, the second-order and third-order branches show considerable irregularities, with knoblike terminal swellings and dendritic excrescences (Grossman et al., 1973). The general appearance of this dendritic arborization is somewhat brush-like in appearance and has given rise to the additional descriptive label of "tufted." The axon, of which there is only one per cell, is myelinated and, so far as presently observed, devoid of collateral branching. However, it must be remembered that myelinization, as well as their probable fineness, might make the existence of collaterals difficult to observe in Golgistained material.

Several researchers, notably Grossman et al. (1973) and Kriebel (1975), have suggested the existence of certain subclasses of the general class of lateral geniculate TCR cells. Grossman has, for example, described a radiate dendritic pattern common to certain TCR cells located more medially in the nucleus. Kriebel's observations, on the other hand, prompted him to describe both a Type I cell and a complementary version of this cell, the Type II cell, which appeared to have a restricted location in the middle one-third of the anterior-posterior dimension of the nucleus. While it is of obvious importance to clearly specify the morphological characteristics of the various neurons within any particular nucleus, it is also important to proceed with some caution when suggesting different varieties of cells due to the vagaries of the Golgi technique itself. Because of this, it would seem prudent to confirm suspected morphological differences by other ultrastructure and perhaps electrophysiological criteria. Unfortunately, this yet remains to be done relative to the TCR cell of the dorsal portion of the lateral geniculate nucleus. Accordingly, the position adopted here is that the TCR cells represent a rather homogeneous group of neurons within the dorsolateral geniculate nucleus.

Turning to the intrinsic neuron, there appears to be, unlike the TCR cell, considerable agreement that intrinsic neurons represent a rather homogeneous ensemble. However, similar to the TCR group, the intrinsic neurons have received various labels. For example, they have been termed PA cells for pseudoamacrine (Rafols \& Valverde, 1973), Class B cells (Grossman et al., 1973), PSD cells for presynaptic dendritic cells (Lieberman, 1972, 1973; Lieberman \& Webster, 1972) and Type III cells (Kriebel, 1975), although in this latter instance the description appears to more closely resemble the radiate TCR cells of Grossman. The classic interneuron, the Golgi Type II neuron, would not seem to be an appropriate label in the present instance, since the majority of the anatomical observations have failed to observe the presence of an axon. Principally because of this, and since it appears most descriptive of the neuron's synaptic arrangement, it is presently suggested that 
the intrinsic neuron of the dorsal portion of the lateral geniculate nucleus be labeled the PSD cell.

In terms of distribution, the PSD cell would appear to reside over the entire nucleus with some slight possibility of a concentration near the external boundaries (Lieberman, 1973). The size of the somata of the PSD cells is quite small (approximately $10 \mu$ ) and somewhat ellipsoid in shape. The dendritic pattern presents few, but rather long, dendrites, with minimal branching. Close to the somata, the dendrites are relatively smooth, but produce considerable enlargements, as well as stalks with terminal enlargements further out. These enlargements then give rise to the P-boutons or dendritic synaptic terminals. The dendrites appear to be preferentially oriented along either the dorsoventral axis or the anterior posterior axis, which corresponds to the longitudinal fiber system and the electrophysiologically defined retinal projection lines previously described. With regard to the possible lamination within the rat's LGNd, it must be noted that the pattern of dendritic branching defies any sort of boundary definition. Finally, while the PSD intrinsic neuron has been described as anaxonal and will be so accepted here, it must again be emphasized that the Golgi technique is not particularly noted for impregnation of myelinated and/or very small caliber fibers.

\section{Synaptic Morphology}

Description of synaptic morphology within the lateral geniculate nucleus has also been largely restricted to the dorsal portion of this thalamic area. Moreover, and similar to descriptions of cellular morphology, there appears to be no paucity of ingenuity relative to classification schemes, even though synaptic vesicles and mitochondria appear to be the only reliable characteristics for distinguishing between the LGNd synapses in rat. For example, one scheme rests principally on the shape of synaptic vesiclesspheroid or flat (S or F) - and the density of the mitochondria-dense or pale (D or P). On the basis of these features, it is possible to distinguish SP-terminals, SD-terminals, and F-terminals as well as SN-terminals which are apparently devoid of mitochondria but contain spherical synaptic vesicles (Lund \& Cunningham, 1972). It is also suggested that there is a quantitative distinction within the F-terminal group, depending upon whether or not the synaptic vesicles are more or less flattened, the F1 terminal or F2 terminal, respectively (Lund \& Cunningham, 1972).

A second classification system, suggested by Lieberman and his associates (1972, 1973, 1974), is also based principally on the shape of synaptic vesicles but, in this case, the defined terminals have been specifically related to the afferent and efferent projections of the dorsal portion of the lateral geniculate nucleus. According to Lieberman, synapses within the LGN contain either round synaptic vesicles or flattened synaptic vesicles, with two distinctive types of synapses with round vesicles, namely the R-boutons and the SR-boutons, and two distinct types of synapses with flattened synaptic vesicles, namely the F-boutons and the P-boutons. The $\mathrm{R}$-boutons are rather large intraglomerular axon terminals containing large mitochondria. The SRboutons, on the other hand, are smaller terminals principally forming Gray Type I synapses in the extraglomerular space. The F-boutons show quite flat, somewhat cylindrical vesicles and are only presynaptic. These terminals most probably correspond to the F1 synaptic terminals described by Lund and Cunningham (1972). The other terminals, containing flattened vesicles, the P-boutons, show synaptic vesicles that are predominantly more discoid in shape with extremely few flattened or small circular profiles. The P-bouton, thus, probably corresponds to the F2 terminal described by Lund and Cunningham (1972). The P-boutons, unlike the F-boutons, can be both pre- and postsynaptic.

Relating these terminals to the afferent and efferent projections of the LGNd has largely been a matter of detecting the degeneration pattern at different times following enucleation and visual neocortical lesions. Thus, the R-boutons show degeneration following enucleation and are therefore considered to represent the axon terminals of retinal ganglion neurons, whereas the SR-boutons undergo degeneration $24 \mathrm{~h}$ following visual neodecortication and are, thus, most probably the terminal processes of corticofugal neurons. Two to 3 days following visual neodecortication, the major degenerating elements are the dendritic processes of the TCR neurons. The P-bouton, on the other hand, has been directly traced with the electron microscope to the dendritic shafts and somata of the previously described PSD neuron, i.e., the LGNd interneuron. With regard to the F-boutons, these do not undergo degeneration following either enucleation or visual neodecortication, and since they have not been traced to intranuclear perikarya, it is assumed that they represent an extrageniculate neuron other than a retinal or cortical afferent.

The synaptic arrangements that may be shown by these elements are quite complex but may be generally categorized as encapsulated (the glomerulus) and nonencapsulated. The encapsulated synaptic arrangement is typified by an outer, surrounding glial membrane composed of astrocytes. Within the area encapsulated by this glial membrane are the dendritic processes of a TCR cell, P-boutons, R-boutons, and, to a much lesser extent, F-boutons. Typical of the intraglomerular synaptic arrangement is the so-called triplet involving a R-bouton, P-bouton, and the dendritic process of the TCR cell. The central element 
of the triplet is the P-bouton upon which synapses the R-bouton, or the retinal afferent, while the Pbouton itself synapses on the dendrite of the TCR cell. Additionally, the retinal afferent may also synapse directly on the TCR dendrite in addition to having the serial synaptic arrangement of the triplet. The F-bouton, when present, synapses principally on P-boutons and the dendritic processes of the TCR cell; however, their presence within the encapsulated synaptic area is greatly outnumbered by the P-bouton - on the order of at least 10 to 1 (Lieberman \& Webster, 1974).

Finally, it should be noted that a glomerulus is not necessarily the exclusive property of only a single TCR cell, since both degenerating and normal TCR dendritic processes have been observed within a single encapsulated zone following restricted neocortical lesions (Lieberman \& Webster, 1974).

Outside the encapsulated synaptic areas of the LGNd, in the extraglomerular neuropile, the P-bouton is only occasionally observed while the F-bouton is quite abundant. And this abundance is reflected in a variety of synaptic relations with the initial axon segment, somata, and the proximal and distal dendritic shafts of the TCR cells. In fact, according to Lieberman and Webster (1974), the F-bouton is the principal presynaptic process forming axosomatic synapses within the LGNd. The SR-boutons, that is, the terminal processes of corticofugal neurons, also extend throughout the extraglomerular area of the LGNd. These terminals principally establish Gray Type I contacts with small- and medium-size dendrites. However, it should be noted that these dendritic processes are not those of the PSD neuron, since degenerating terminals following visual decortication have never been observed in contact with presynaptic dendrites or P-boutons. Thus, the interneuron of the LGNd is apparently not the direct recipient of corticofugal influence.

Before leaving the lateral geniculate nucleus, it is finally necessary to point out what appears to be a topographical arrangement of encapsulated zones and nonencapsulated zones (Lund \& Cunningham, 1972). The encapsulated zones appear to be restricted to the outer shell of the nucleus and are organized into two layers. The outermost layer is associated with contralateral retinal input, while the second layer is presumably associated with ipsilateral retinal input. The nonencapsulated zones reside in the medial one-third of the lateral geniculate nucleus and also between the two encapsulated zones. Both crossed and uncrossed retinal input contribute to the nonencapsulated area. This general topography, of course, corresponds quite closely to the patterns of degeneration described by Goodman and Horel (1966) and Hayhow et al. (1962)-see Figure 5-and once again attests to the complexity of the rat LGNd and its potential as a prelude to higher mammals.

\section{SUPERIOR COLLICULUS}

\section{General Considerations}

Proceeding along the course of the axons of retinal ganglion cells, the next major nuclei of the rat's primary visual system are the superior colliculi located on the dorsal surface of the mesencephalon in an area generally described as the tectum. The pair of superior colliculi are distinguished as two bumps immediately anterior to another pair of bumps, the inferior colliculi which are concerned principally with auditory functions. Viewing the dorsal surface of the rat's brain, the superior colliculi are all but obscured by the overlying cerebral hemispheres, while the inferior colliculi are readily observed between the posterior extent of the hemispheres and the cerebellum. Considering our standard-sized rat, each superior colliculus measures approximately 2.5 to $3 \mathrm{~mm}$ in the rostrocaudal dimension and shows a similar extent in the mediolateral dimension. The dorsoventral extent of the superior colliculus is approximately 1.2 to $1.5 \mathrm{~mm}$ when all of its layers are considered. The most rostromedial extreme of the superior colliculus is continuous with the thalamus, while the rostrolateral border, principally the stratum opticum, blends with the brachium of the superior colliculus.

In terms of its gross structural character, Cajal (1954) has suggested that the superior colliculus is subdivided into a series of zones on the basis of cellular morphology. While Langer and Lund (1974, see below) have adopted Cajal's scheme, it is more common to subdivide the superior colliculus into a number of alternating strata of myelinated fiber processes and neuropile. According to this latter scheme, the superior colliculus has seven distinct layers, with the most superficial layer quite poorly developed in the rat. The layering of the superior colliculus is particularly clear in the material presented by König and Klippel (19.63), who used tissue stained with Sudan Black as photographic negatives to prepare their stereotaxic atlas. The seven layers are, from dorsal to ventral, the stratum zonale, stratum griseum superficiale, stratum opticum, stratum griseum mediale, stratum album, stratum griseum profundum, and the stratum album profundum, or alternatively, the zonal layer, the superficial gray layer, the optical layer, the medial gray layer, the white layer, the deep gray layer, and the deep white layer. Typically, these layers are grossly collectivized into the superficial layers (the zonal layer, the superficial gray layer, the optical layer, and the uppermost portions of the medial gray layer), which are intimately associated with the primary visual centers of rat, and the deep layers (the major portion of the medial gray layer, the white layer, the deep gray layer, and the deep white layer), which receive input from the reticular formation, cerebellum, and cervical portions of the spinal cord as well as providing 
the major efferents of the superior colliculus (Lund, 1969). In the present instance, we will, of course, be principally concerned with the superficial layers.

In somewhat more detail, the zonal layer is a rather poorly defined layer in the rat composed of a few tangentially oriented myelinated fibers and cell bodies. The superficial gray layer, in contradistinction, is a rather distinct layer approximately 175 to $200 \mu$ thick. It is comprised of numerous small cells and some myelinated axons, with their orientation perpendicular or oblique to the surface of the superior colliculus. The optical layer is similarly a quite distinct layer of approximately 100 to $150 \mu$ thickness. The optical layer is composed principally of myelinated fibers which assume a rostrocaudal orientation with a few rather large cell bodies intermixed amongst the fibers. As previously indicated, the optical layer is continuous with the brachium of the superior colliculus, which in turn is a continuation of the optic tract, as will be more fully described below. The medial gray layer is a layer of cell bodies principally of the multipolar variety (Langer \& Lund, 1974). While the major portion of the medial gray layer is typically considered with the deeper, nonvisual, layers of the superior colliculus, certain investigators have noted the termination of both retinofugal and corticofugal fibers in this layer, at least in Nautastained material. Accordingly, we have opted to include the superficial portion of the medial gray layer with those layers of the superior colliculus directly related to the primary visual system of the rat.

\section{Afferent}

\section{Afferent-Efferent Projections}

The afferent input to the superficial layers of the superior colliculus is predominantly from three sources: the contralateral and the ipsilateral retina and the ipsilateral visual neocortex. The retinal afferents considerably outnumber the cortical afferents, with, of course, the contralateral retinal input, in turn, being much greater than the ipsilateral retinal input. While there would appear to be general agreement concerning the origin of these efferent fibers, their specific termination within the various layers of the superior colliculus is open to some debate. As with the vagaries noted concerning the lateral geniculate nucleus, the debate is in a major part precipitated by the particular histological analysis used to define the termination.

Contralateral retina. The afferents from the contralateral retina arrive at the superior colliculus via the brachium of the superior colliculus, which is a continuation of the optic tract. The brachium of the superior colliculus itself courses, in succession, over the posterior lateral nucleus of the thalamus, the pretectal nucleus, and the lateral nucleus of the optic tract before reaching the superior colliculus to dom- inate the optical layer of this structure. Utilizing Nauta methods following contralateral enucleation, there appears to be heavy preterminal degeneration within the optical layer, along with considerable axonal degeneration and, in both the superficial gray layer and the medial gray layer, somewhat lighter patterns of degeneration (Goodman et al., 1973; Goodman \& Horel, 1966; Hayhow et al., 1962).

However, in contradistinction to material prepared in accord with the Nauta methodologies, data from the electron microscope (Lund, 1969, 1972) indicate a qualitatively different pattern of terminal degeneration. In this case, the heaviest terminal degeneration following contralateral enucleation occurs in the upper $100 \mu$ of the superior colliculus, i.e., principally in the zonal layer and the dorsal one-half of the superficial gray layer. Extremely slight degeneration is observed within the optical layer itself, and none deeper. Lund (1969) speculates that the reason for these diametrically different patterns of degeneration rests principally on the fact that the Nauta methodology stains not only terminals but also axons and that, within the optical layer, the degenerating axons may be confused for preterminal degeneration.

Ipsilateral retina. Considering the ipsilateral retinal afferents, there appears to be somewhat better agreement and the discrepancies which do exist are principally quantitative. For example, Goodman et al. (1973) suggest that the ipsilateral afferents arrive at the superior colliculus via two routes, a rostral route and a lateral route. The rostral route passes caudally through the lateral geniculate from the optic tract and produces heavy preterminal degeneration in the medial portion of the rostral one-third of the optical layer. The lateral route, on the other hand, runs within the brachium of the superior colliculus and produces quite a bit less degeneration, and while also restricted to the rostral one-third of the superior colliculus is, in this case, confined to the lateral onehalf of the optical layer. Data presented by Hayhow et al. (1962) are in general agreement with Goodman and his co-workers so far as the lateral route to the superior colliculus is concerned, but these observers did not describe the rostral entrance. Additionally, the degeneration pattern observed with the electron microscope (Lund, 1972) is in general agreement with the Nauta-prepared material.

Ipsilateral cortex. The ipsilateral cortical projection to the superior colliculus is substantially less than that from the retina ganglion cells. The projection itself generally courses through the internal capsule where it enters the lateral part of the cerebral peduncle to travel within it until entering the optic tract. Once within the optic tract, the corticofugal fibers enter the superior colliculus either via the brachium or via the lateral geniculate nucleus and the pretectal region, i.e., the rostral route of Goodman et al. (1973). 


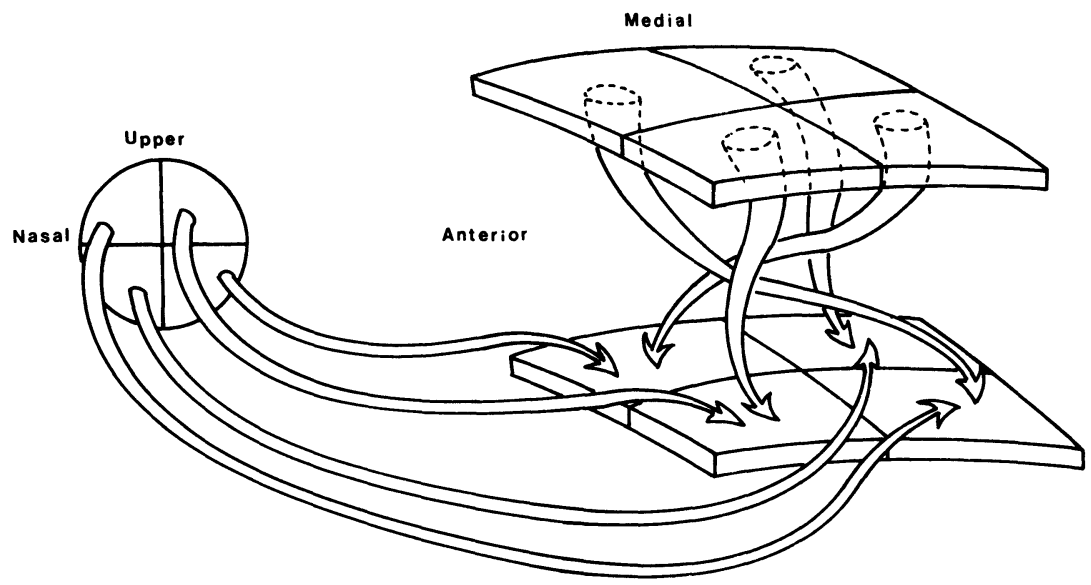

Figure 10. Retinofugal and corticofugal projections to the superior colliculus. Backside of right retina is indicated by circle on left and left visual neocortex by upper diagram.

Following small lesions restricted to area 17 of the neocortex (Nauta \& Bucher, 1954), the pattern of degeneration is confined to the lateral two-thirds of the superior colliculus, where its vertical extent is from the zonal layer to the medial gray layer. If, on the other hand, the cortical insult is somewhat more extensive (Goodman \& Horel, 1966), the pattern of degeneration involves the entire mediolateral extent of the superior colliculus and is principally confined to the optical layer. However, it must be noted that the lesions in this latter case involved only "normal" precautions against invading the underlying white matter and extended well beyond area 17 . This, then, might indicate that the medial portions of the superior colliculus are the principal projection areas for cortical fibers residing outside of area 17 , although the researches needed to establish this have yet to be completed. It is, however, interesting to note that the medial portion of the superior colliculus is also the recipient of afferents from the ventral lateral geniculate nucleus-a portion of the LGN which receives retinal input but does not project to primary visual neocortex. Finally, there is again very good agreement between the Nauta prepared material and that analyzed with the electron microscope.

\section{A Word on Topography}

There is virtually a complete correspondence between the retinal projection to the superior colliculus and the visual neocortex. That is, the retina maps over the visual neocortex in such a manner that the areas receiving particular retinal projections project to areas of the superior colliculus receiving similar retinal projections. Considering, first, the retinal projection, there is little anatomical data, but the electrophysiological results (Siminoff, Schwassmann, \& Kruger, 1966) provide the general organization picture shown in Figure 10. As can be seen from this figure, the temporal retinal quadrants project to the anterior portion of the superior colliculus and the nasal quadrants project to the posterior portions of the superior colliculus. The lower retinal quadrants project medially and the upper retinal quadrants project laterally.

The cortical projection to the superior colliculus has been analyzed with anatomical techniques by determining the effects of a number of very small lesions placed within primary and extraprimary visual neocortical areas. Projections from the primary visual cortex are restricted principally to the superficial layers of the superior colliculus with, referring again to Figure 10, the anterior quadrants projecting to the lateral area of the superior colliculus and the posterior quadrants projecting to the medial area of the superior colliculus (Lund, 1964, 1966). The lateral two quadrants of the visual neocortex, in turn, project to the rostral area of the superior colliculus, while the medial two quadrants project to the posterior portion of the superior colliculus. The extraprimary visual neocortex anterior to area 17 , on the other hand, projects to the deeper layers of the superior colliculus, with the more lateral portions of the projection being restricted to the rostral portion of the superior colliculus and the more medial portions of the projection being restricted to the posterior area of the superior colliculus.

\section{Efferent}

The major efferent fibers of the superficial layers of the superior colliculus project both to the thalamus and to deeper layers of the superior colliculus. The principal thalamic nuclei are the ventral portion of the lateral geniculate nucleus and the posterior lateral nucleus. The deeper layers of the superior colliculus are, of course, the medial gray layer, the white layer, the deep gray layer, and the deep white layer. These 
deep layers of the superior colliculus then form efferent connections to brainstem areas and additionally to posterior regions of the thalamus.

\section{Cellular Morphology}

Intrastructural Morphology

The description of cell types within the superior colliculus rests upon Golgi-prepared material, with the most recent description offered by the excellent observations of Langer and Lund (1974). However, while the descriptions provided by Langer and Lund are most detailed, they are, in one sense, somewhat difficult to become accustomed to since they are referenced to Cajal's zonal organization of the superior colliculus. Cajal's scheme divides the more commonly defined superficial layers of the superior colliculus into three major zones on the basis of particular cell types. The first zone is the zone of horizontal cells and comprises the zonal layer and the upper portion of the superficial gray layer. The next deeper zone, according to Cajal, is the zone of vertical cells which corresponds to the deep portion of the superficial gray layer. The final zone is the zone of optical fibers, which is, of course, the optical layer according to the more common classification system. Essentially, then, since the zonal layer is quite poorly developed in the rat, Cajal's scheme deviates from our previous description of the superior colliculus simply by dividing the superficial gray layer into an upper portion, the zone of horizontal cells, and a lower portion, the zone of vertical cells.

With this zonal classification in mind, there are three major categories of cells within the superior colliculus. These major categories are the horizontal cells, of which there appear to be one type, the vertical cells, of which there appear to be four types with two of these types each having two subtypes, and the stellate cells, of which there is only one type. Summing across categories, types, and subtypes, there are, then, eight distinct cell morphologies within the superior colliculus distinguishable on the basis of the position of the cell body, characteristics of the dendrites and axons, and the relationship between the dendrites and the somata. These eight cells may be summarized as follows:

(A) Horizontal cells

(B) Vertical cells

(1) Marginal type

(2) Piriform type

(3) Narrow field vertical cells

(a) Vertical fusiform type

(b) Pyramidal type

(4) Wide field vertical cells

(a) Type II ganglion

(b) Type III ganglion

(C) Stellate cells

It must, however, be quickly noted that the present assignment of particular cells to the major categories of horizontal, vertical, and stellate represent the present author's interpretation, since after a description of the main categories, Langer and Lund concentrate on the details of individual cell types without, in some cases, explicitly assigning a cell to a general category. Our assignment is what we believe to be reasonable, but the interested reader is urged to consult the original source.

Horizontal cells. The cell bodies of the horizontal cells are principally fusiform with diameters of approximately $10 \mu$. For the most part, the cell bodies are found within the superficial $250 \mu$ of the superior colliculus (the zone of horizontal cells), although some may be observed in the zone of optical fibers. The dendritic pattern typically shows two primary branches approximately 10 to $15 \mu$ long and $2 \mu$ thick but of somewhat irregular caliber. These primary dendrites branch into several higher-order dendrites, typically $1 \mu$ thick and of a more consistent caliber. The dendritic shafts have few spines or knobs, and where these do exist they are grouped into clusters. The axon of the horizontal cell may originate from the cell body, a primary dendrite, or a secondary dendrite, and typically shows an irregular course with considerable branching within the zone of horizontal cells. It is of some interest to note that, while the orientation of the dendrites of the horizontal cells may vary from region to region, the preferred axis appears to lie along the meridians of the visual fieldan organization reminiscent of the longitudinal system described by Montero et al. (1968) for the dorsal portion of the lateral geniculate nucleus.

Vertical cells. Of the cells exhibiting a vertical dendritic organization, there are four general types within the superior colliculus. These are the marginal cells, the piriform cells, the narrow-field vertical cells, and the wide-field vertical cells, with the latter two types each having two subtypes. The marginal cells exhibit an ovoid cell body approximately 5 to $8 \mu$ in diameter and are located in the uppermost regions of the zone of horizontal cells, i.e., just below the rostrocaudal fibers of the zonal layer. The dendrites of these cells, of which there may be from one to five branches but typically just two, extend some $150 \mu$ below the soma in a branching and radiating pattern in a field which may extend some $75 \mu$. The dendrites may be either smooth, having a "more open and delicate pattern," or spiny, with, in some cases, the spines completely covering the dendrites and soma. It is worth noting that, with the exception of the horizontal cells, all of the cells within the superior colliculus may, in fact, be dichotomized into either smooth or spiny types. The axons of the marginal cells do not normally extend below the zone of horizontal cells, and in general resemble other local axons, having a very fine caliber, many branches, no overriding direction, and many en passant and terminal varicosities. 
The second type of vertical cell, the piriform cell, also has an oval or cup-shaped soma, but is somewhat larger in diameter $(10$ to $15 \mu)$; it occupies a narrow band along the deep margin of the zone of horizontal cells - that is, about midway through the superficial gray layer. The dendrites usually number from two to five and arise from the dorsal surface of the soma to travel through the zone of horizontal cells and terminate just beneath the surface of the superior colliculus. These dendrites branch frequently and sometimes run obliquely or even horizontally, but rarely, if ever, descend below the level of the soma. As with other types of superior colliculus cells, there are both smooth and spiny piriform cells. The axon of the piriform cell most frequently originates from the base of the soma and can often be traced downward through the zone of vertical cells. Typically, the axon is thin and smooth with only occasional en passant varicosities.

The third type of vertical cell, the narrow-field vertical cell, is composed of two distinct subtypes of cells: the vertical fusiform cell and the pyramidal cell. The vertical fusiform subtype has been further classified as either superficial, intermediate, or deep, depending upon the location of the soma within the vertical cell zone. Independent of this distinction, however, the vertical fusiform cell has a soma approximately 10 to $20 \mu$ in diameter and yields two ascending dendritic trunks and two descending dendritic trunks. From these trunks arise, respectively, the superficial dendritic field and the deep dendritic field, with each being between 100 and $200 \mu$ in width, although the superficial field is typically narrower. The axon of the vertical fusiform cell commonly originates from one of the lower ordered dendrites and courses deep toward the ganglion zone of the superior colliculus, as described by Cajal. In general, the axons are similar to other intrinsic axons, although somewhat thicker than those of the marginal cells or the horizontal cells. The pyramidal subtype of the narrow field vertical group has a soma approximately $15 \mu$ in diameter and is principally located in the deeper one-half of the zone of vertical cells. As with the vertical fusiform cells, the dendritic pattern provides both a superficial and a deep field. The superficial field is narrow and cylindrical, and develops from one or two thick apical dendrites. The deep field is somewhat reduced and restricted to a small field circumscribing the cell body itself. The axon of the narrow-field vertical pyramidal cell typically originates from the soma or a lower order dendrite and runs to the deeper zones of the superior colliculus.

The final type of vertical cell is the wide-field vertical cell which also has two subtypes: the Type II ganglion cell and the Type III ganglion cell. The Type II ganglion cell has a soma of approximately 15 to $25 \mu$ and is located along the deep margin of the zone of vertical cells. The three to seven primary dendrites of this cell may originate from any portion of the cell but are usually seen at the dorsal or lateral surface. The dendrites typically course vertically or obliquely toward the surface of the superior colliculus. The axons of these neurons originate from the soma or a lower-order dendrite and may project either to the superficial areas of the superior colliculus or to the deep areas of the superior colliculus and often branch to form an arborization as wide as the dendritic field. In contradistinction, the Type III ganglion cell has a soma somewhat larger (20 to $25 \mu$ ) and is principally located in the upper portion of the zone of optical fibers. The Type III ganglion cell has typically three to six primary dendrites, some of which extend below the soma. The axon invariably goes to the deeper portions of the superior colliculus.

Stellate cell. The third major category of cells within the superior colliculus is the stellate cell, which is the most frequent cell type below the zone of optical fibers. The stellate cell is characterized by the fact that its dendrites arise from all portions of the soma, extend symmetrically from their points of origin, and do not show any particular orientation. The axon of the stellate cell may have either a local or a distant distribution.

Axons. Langer and Lund (1974) also distinguish two general categories of axons within the superior colliculus, intrinsic axons and extrinsic axons, with each category being composed of two types. The types of intrinsic axons are descriptively labeled the smooth and direct intrinsic axon and the branched and rough intrinsic axon. The smooth and direct variety, as the name implies, shows few collaterals and extends to and beyond the deep areas of the zone of optic fibers. The branched and rough variety, on the other hand, often produces a dense mesh of collateral fibers with little sense of direction.

The two types of extrinsic axons are the retinal afferents and the cortical afferents. While Langer and Lund suggest that it is somewhat difficult to distinguish the neocortical axons using Golgi prepared material, the retinal axons are quite easy to detect. These enter the zone of optical fibers (the optical layer) and transverse this zone for some distance before turning vertically to extend toward the surface of the superior colliculus. As these retinal axons pass through the zone of vertical cells, there are numerous en passant varicosities and, when the axon finally reaches the zone of horizontal cells, frequent branching. It should be obvious that this Golgi definition of the retinal afferent is directly complementary to Lund's (1969) suggestion that the major preterminal degeneration following enucleation is within the most superficial $100 \mu$ of the surface of the superior colliculus. 
Finally, it is of some interest to note that Valverde (1973), using very young mice (7-15 days of age), distinguishes cell types within his Golgi material quite similar to that described by Langer and Lund (1974). Valverde made no attempt to distinguish different cell types on the basis of dendritic arborization but, rather, concentrated on axonal characteristics. On this basis, there are apparently three types of neurons distinguishable in the very young mouse, with two of the types being indigenous to the superior collicus superficial layers, i.e., exhibiting short axons, while the third is somewhat more variable but generally shows a long projecting axon. The two short-axon cells, which Valverde classifies as horizontal cells and short-axon cells, most probably correspond to Langer and Lund's description of marginal cells and horizontal cells, respectively. Additionally, the long projecting neurons of Valverde appear quite similar to what Langer and Lund have classified as wide-field neurons. In view of the vagaries of the Golgi methodology as well as the possible differences between mouse and rat, this degree of correspondence is somewhat remarkable.

\section{Synaptic Morphology}

With the electron microscope, it is possible to define three general classes of synaptic terminals within the superficial layers of the superior colliculus. These terminals have been classified by Lund (1969) as Class I terminals, Class II terminals, and Class III terminals, with the Class II terminal having three distinguishable subcategories, a, b, and c. The Class I terminals account for approximately $60 \%$ of the synapses within the superficial layers of the superior colliculus. Generally, the terminals are approximately $1 \mu$ in diameter and are associated with unmyelinated axons, which are difficult to trace for any great distance. Typically, the terminals contain agranular round vesicles of approximately $500 \AA$ in diameter which are aggregated adjacent to the membrane specialization. Only infrequently are presynaptic dense projections noted. The postsynaptic component of the Class I terminals are small clear profiles, most likely dendritic branches and/or their associated spines. The Class I terminal is particularly numerous near the surface of the superior colliculus and is frequently involved in serial synaptic arrangements where the Class I terminal is presynaptic to a terminal containing a flattened vesicle which, in turn, is presynaptic to a clear profile. At deeper levels of the superior colliculus, the serial synapse is extremely rare.

The Class II terminals, as a group, present polymorphic agranular vesicles which are sometimes flattened or cylindrical, showing dimensions of approximately $400 \times 200 \AA$. The Class IIa terminals occur throughout the superficial layers of the superior colliculus and are typically associated with processes of less than $1 \mu$ in diameter, although deeper in the superficial gray layer these processes may be somewhat larger. While the Class IIa terminal accounts for most of the axosomatic synapses within the superior colliculus, they may also be presynaptic to large dendrites. The Class IIb terminals are associated with dendrites less than $1 \mu$ in diameter and exhibit small groups of vesicles adjacent to the membrane specialization. These terminals were typically presynaptic to other structures and postsynaptic to both Class I and Class II terminals. The Class IIc terminals are attached to processes approximately $1 \mu$ in diameter and are presynaptic to clear profiles. The Class IIc terminal is also postsynaptic to Class I and Class II terminals. In contradistinction to the Class IIb terminals, the Class IIc terminal profiles contain neurotubules, mitochondria, and agranular reticulum and are reminsicent of the lateral geniculate nucleus PSD terminals, since they are clearly traceable to dendritic shafts.

The Class III terminals as described by Lund (1969) occur quite infrequently and are typified by a high proportion of large granular vesicles.

On the basis of synaptic morphology, one may thus distinguish Class I terminals, which contain agranular round vesicles, Class II terminals, which contain flattened, cylindrical synaptic vesicles, and Class III terminals, which contain large granular vesicles. Some notion of how these terminals are interrelated is shown by the different degeneration patterns following enucleation and neocortical lesions. Three days following enucleation, for example, there is a wide-spread appearance of glycogen granules in the affected synaptic terminals. The terminal degeneration is most pronounced in the superficial $100 \mu$ of the superior colliculus, becoming less and less dense as one moves deeper and deeper within the superior colliculus, until, at the optical layer, degenerating terminals are extremely rare. All of the terminals appear to have round vesicles, most of which are associated with processes of less than $1 \mu$ in diameter, that is the Class I terminal. Commonly, the postsynaptic elements associated with these degenerating terminals are small clear profiles, Class IIa terminals, and, in a few cases, the surface of larger dendrites.

Subsequent to primary visual neocortical lesions, a different pattern of degeneration occurs. In this case, the reaction is principally an electron dense response and the affected terminals always contain round synaptic vesicles approximately 500 to $600 \AA$ in diameter. The density of this degeneration is considerably less than that following enucleation. Moreover, the degeneration is concentrated in the deepest $100 \mu$ of the superficial gray layer with some involvement of the most dorsal portion of the optical layer. 
Rarely, if ever, is degeneration seen in the most superficial $150 \mu$ of the superior colliculus or deeper than the optical layer, unless, in the latter case, the neocortical lesion extended beyond the anterior border of area 17. The postsynaptic structures associated with these electron dense terminals are typically small, clear profiles with no indication that the corticotectal terminals make axosomatic contacts or that they are postsynaptic to other terminals.

Finally, it is perhaps important to note that the degeneration observed within the superior colliculus following enucleation and visual neodecortication, like the degeneration patterns within the lateral geniculate nucleus, typically does not involve synaptic terminals exhibiting flattened synaptic vesicles.

\section{VISUAL NEOCORTEX}

\section{General Considerations}

The rat's neocortex is similar to the neopallium of all mammals in that there are six definable layers. From surface to depth, these are labeled the plexiform layer, the outer granular layer, the layer of medium-sized pyramidal cells, the inner granular layer, the layer of large pyramidal cells, and the layer of polyhedral cells (Krieg, 1946). While layers 2 and 3 in some cases may be indistinguishable, it is nonetheless possible on cytoarchitectural criterion to partition the surface of the rat's brain into a number of areas rivaling the quantity typically assigned to higher mammals. Although there may be some disagreement on certain of the details of certain of these neocortical areas, there is considerable agreement that the primary visual cortex of the rat is located on the posterior one-third of the dorsal surface of the cerebral hemisphere.

Early specification of the primary visual area was accomplished by an analysis of the retrograde degeneration following discrete lesions of the neocortex (Lashley, 1934). These data clearly demonstrated that the cortical projection of the dorsal portion of the lateral geniculate nucleus is confined to an area of the neocortex typified by densely packed cells within the fourth layer. This is, of course, area 17 (area striata) as described by Krieg (1946), and it is continuous on its medial border with area 18 and on its lateral posterior border with area 18A (Figure 11), both of which are intimately related to the rat's primary visual system through direct fiber connections to area 17. It must, however, be noted that, while the boundary of area 17 is easily distinguished medially, it is not so easily distinguished along its anterior and lateral borders, where there is considerable blending with the adjacent cortical areas.

More recently, the primary visual area has been defined by the transport of radioactively labeled proteins (Drager, 1974) and electrophysiological map- ping (Adams \& Forrester, 1968; Montero, 1973; Montero, Rojas, \& Torrealba, 1973). In each of these cases, the presented data show quite good agreement with the earlier anatomical observations of K.S. Lashley and W.J.S. Krieg. The electrophysiological data show that the primary visual area extends rostrally approximately $6.2 \mathrm{~mm}$ from the occipital pole and has a medial border approximately 1 to $2.5 \mathrm{~mm}$ from the midline while its lateral border is approximately $5.8 \mathrm{~mm}$ from the midline (Montero, 1973). There is also a second visual area (here called V-II) juxtaposed laterally to the primary visual area (V-I), which may in some cases make the lateral boundary electrophysically less distinct. However, V-II presents a mirror image of the retinal map of V-I, so its definition is not as difficult as it would at first seem.

\section{Afferent}

\section{Afferent-Efferent Projections}

The afferents to area 17 originate from two major sources (Nauta \& Bucher, 1954), the TCR neurons of the dorsolateral geniculate nucleus and the commissural fibers from the contralateral striate neocortex. As previously noted, the axons of the TCR cells exit the lateral geniculate nucleus rostrolaterally, to travel in a ventral direction and loop around the stria terminalis in front of the hippocampal flexure (Riback \& Peters, 1975). The fibers are found in the caudal limb of the internal capsule, from where they travel through the caudate nucleus, with some fibers extending as far as the level of the optic chiasma. From here, the fibers turn to enter the white matter below the neocortex anterior and lateral to the striate area and then follow along the dorsal surface of the corpus callosum to terminate in area 17 . This route is, of course, the optic radiation of the rat.

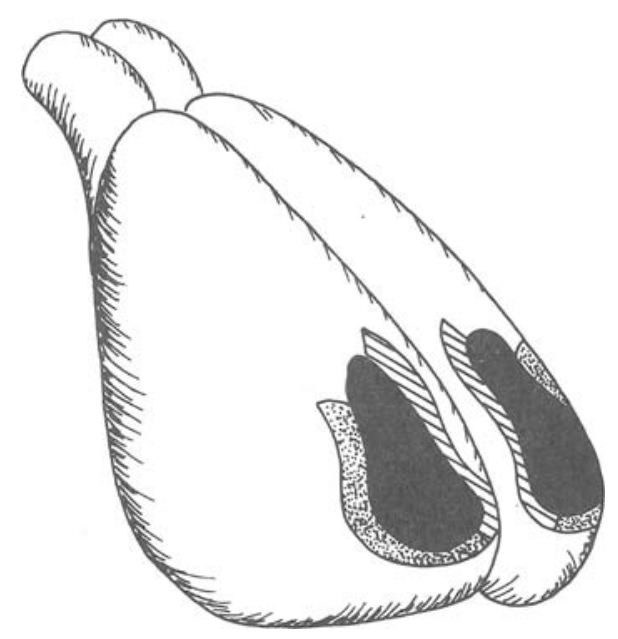

Figure 11. Location of area 17 (solid black), area 18 (striations), and area 18a (stippling) on the posterior portion of the rat's cerebral hemisphere. 
Within the striate area itself, autoradiographic analysis indicates that the termination of the TCR axons is concentrated principally in the deep portion of the third cortical layer and throughout the fourth cortical layer. Additionally, there are minor terminations in the outer portion of the first layer and the upper and lower portion of the sixth layer (Ribak \& Peters, 1975). While there may be some difficulty in distinguishing between silver grains associated with terminals and those associated with axon fibers in layer VI, recent electron microscopic data (Peters \& Feldman, 1976) have generally confirmed this termination site.

\section{Efferent}

There are two general types of area 17 efferent fibers, namely associational fibers and extracortical projection fibers. Considering first the associational fibers, there are three groups; intracortical association fibers, cortico-cortical association fibers, and commissural fibers. The intracortical association fibers are fibers whose axon processes remain wholly within the layered neocortical mantel. The destination of these fibers is area 18 and area $18 \mathrm{a}$, with the heaviest concentration in layers $\mathrm{V}$ and VI and, to a lesser extent, in layers II and III. The axonal processes of the cortico-cortical association fibers, on the other hand, loop down through the white matter and apparently travel only to area 18a (Montero et al., 1973; Nauta \& Bucher, 1954). The terminal distribution of the cortico-cortical fibers within area $18 \mathrm{a}$ is, however, essentially similar to that of the more widespread intracortical fibers.

The commissural fibers, which have been studied in somewhat greater detail, are confined to the caudal region of the corpus callosum. Following restricted lesions of the striate area, these fibers project heaviest to the lateral one-third of area 17 and to an adjoining strip of area 18a. Subsequent to sectioning the corpus callosum itself, however, it is possible to detect light degeneration in area 18 as well as in areas 17 and 18a (Jacobson, 1970). The termination of these fibers innervating area 18 is quite similar to that described by Nauta and Bucher, with the exception that the termination extends to the submacular portion of layer I. Similar results have been found by Lund and Lund (1970) following restricted lesions along the border of areas 17 and $18 \mathrm{a}$ which produces degeneration in the corresponding contralateral area of the neocortex. In accord with other observations, the heaviest degeneration is noted in the deeper portions of layers I and II and in the upper half of layer III. Somewhat less degeneration is also noted in layers V and VI, with very minimal, if any, degeneration in layer IV. Layer IV is, of course, the principal recipient of the TCR axons from the dorsal portion of the lateral geniculate nucleus.

Thus, the commissural fibers show their heaviest termination in upper cortical layers (I, II, and III), while the associational fibers which remain within the same hemisphere show their heaviest termination in the lower cortical layers (V and VI).

Turning to the extracortical projection, this generally follows the optic radiations to a point where certain of the fibers enter the lateral one-quarter of the cerebral peduncle and extend as far as the pons. However, most of the fibers discharge at somewhat higher levels to enter the thalamus, the subthalamus, the pretectal region, and the superior colliculus, as has been previously described when certain of these centers were considered in detail.

\section{A Final Word on Retinotopic Organization}

From both the anatomical data (Lashley, 1934) and electrophysiological data (Adams \& Forrester, 1968; Montero et al., 1973), it is apparent that the retinal input maps over the striate area in a precise topographic fashion. In particular, the rostral portion of area 17 receives input from the superior retina and the caudal portion receives input from the inferior retina. The medial portion of area 17 receives its input from the nasal retina, while the lateral portion receives its input from the temporal retina (see

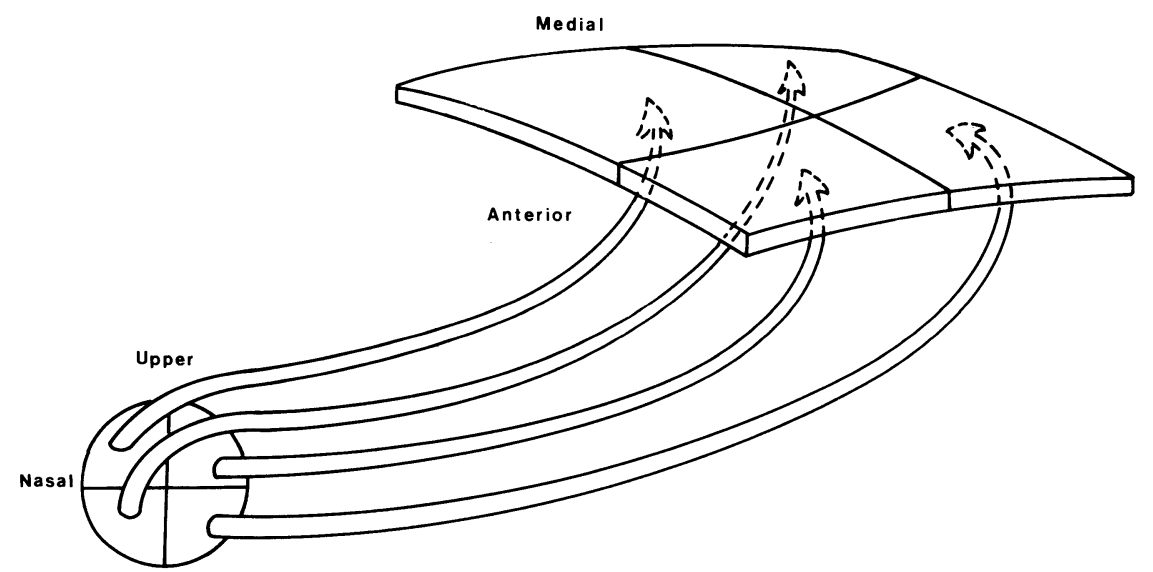

Figure 12. Retinotopic projection to area 17. Circle indicates back of right retina. 

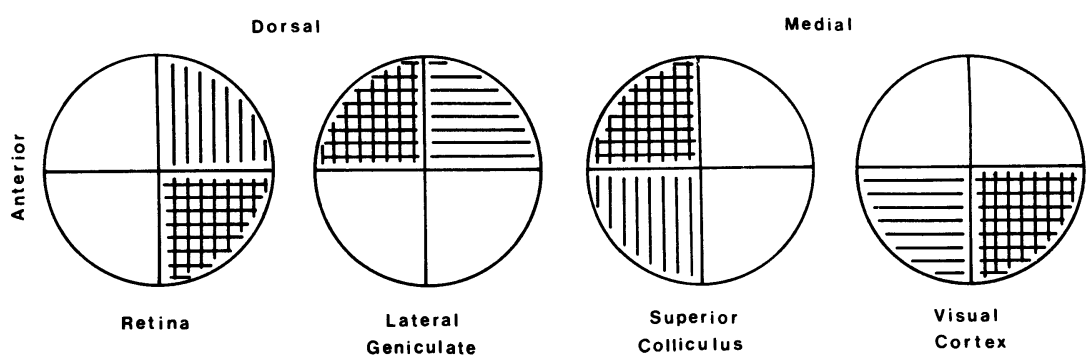

Figure 13. Summary of the retinotopic organization of the dorsal lateral geniculate nucleus, superior colliculus, and visual neocortex. See text for explanation.

Figure 12). The extrastriate areas, on the other hand, similarly show a retinotopic organization, but with some notable differences relative to that observed in area 17. Notably, the receptive fields are quite a bit larger than those of area 17 and the retinotopic organization is the mirror image of that of area 17 (Montero et al., 1973).

A final final word on retinotopic organization. A summary of the retinotopic organization throughout the primary visual system of the rat is presented in Figure 13. This figure presents the retina, dorsolateral geniculate nucleus, superior colliculus, and area 17, from left to right, as four circles. Each circle is divided into four quadrants, with anterior (nasal retina) to the left and posterior (temporal retina) to the right. The upper portions represent the upper retina-dorsal portion of the dorsolateral geniculate nucleus and medial aspect of the superior colliculus and area 17-while the lower portions represent the lower retina-ventrolateral portion of the dorsolateral geniculate nucleus and lateral aspect of the superior colliculus and area 17. Considering first one-half of the retina (temporal in Figure 13), it can be seen that the projection rotates in a counterclockwise fashion as it projects to subsequent visual centers. Turning to a single retinal quadrant (lower nasal in Figure 13), the quadrant alternates between the two quadrants making up the half retina under consideration. For example, with respect to Figure 13 and remembering the clockwise rotation, the indicated quadrant is first behind, then in front of, then behind again, and finally in front of the other quadrant making up the temporal projection of the retina as this moves from one visual center to the next. The figure does not, of course, take into consideration the absolute size of the projections of the various retinal quadrants. Nonetheless, the figure does provide a general picture of the retinotopic organization of the rat's visual system and may be of some benefit in appreciating how the primary visual centers are related not only to the animal's receptor system, but also to each other.

\section{Cellular Morphology}

\section{Intrastructural Morphology}

The cellular morphology and fiber system of the rat's primary visual neocortex has been elegantly described in detail by Krieg (1946), who used the light microscope. Generally, this neocortical region is relatively thin and characterized by numerous granular cells. These granular cells are concentrated in layers II through IV and in layer VI. In terms of thickness, layers II, III, and IV are approximately equal to layers V and VI. Designation of area 17 is based mainly on the distinctive features of layers IV and V. Principally, layer IV is notable for its closely packed granular cells which may form a distinctive stripe in Nissl-stained material to provide the impetus for the label striate cortex. Layer V, on the other hand, contains relatively large, dark-staining pyramidal cells whose equilateral shape is typical of the mammalian visual neocortex. These pyramidal cells are quite sparse in layer $\mathrm{V}$, and the somewhat extensive and open space allows easy recognition of area 17 even when the closely packed granular cells of layer IV may be somewhat difficult to distinguish. Notwithstanding the previous discussion, the fiber processes of area 17 are few and, in fact, are less in number there than in any other primary sensory area of the neocortex.

The paravisual areas, areas 18 and $18 \mathrm{a}$, are quite similar in appearance to that of area 17. That is, there is extensive granulation which all but obscures the laminar form of the neocortex. In general, the prestriate areas are somewhat thinner than the striate area itself, due principally to a decrease in layers II, III, and IV.

The fine structure of the primary visual area of the rat's neocortex has been analyzed by the electron microscope, and two principal types of cells and three principal types of synapses have been described. Considering first the cell types, the electron microscope essentially confirms Krieg's early observations inasmuch as the cells may be generally characterized as pyramidal cells and nonpyramidal or granular cells. The pyramidal cell is, of course, recognized by its shape and apical dendrite, which extends to the surface of the neocortex. There are very few synapses on the proximal portion of this dendrite, or the soma itself, with those that do occur principally containing flattened vesicles. The axon of the pyramidal cell normally exits from the base of the soma, and the 
hillocks are easily identified by the absence of agranular endoplasmic reticulum. Within this area, the synapses again typically contain flattened vesicles. In contradistinction, the nonpyramidal or granular cells often exhibit an irregular shape, but may be generally characterized as round. A predominance of mitochondria is often observed. Both axosomatic and axodendritic synapses are present. The axosomatic synapses typically contain round vesicles, while the dendrites are covered with synapses containing both flat vesicles and round vesicles, although synapses with round vesicles appear to predominate.

\section{Synaptic Morphology}

Considering the synapses themselves, three types may be defined: (1) those containing round agranular synaptic vesicles, (2) those containing flattened agranular vesicles, and (3) a very infrequent type containing dense bodies and membrane-bound granules. The synapses containing round agranular vesicles make synaptic contact principally with dendritic shafts, spines, and branches, as well as, but to a much lesser extent, the cell body itself. The synaptic contacts that are associated with dendrites and dendritic spines show a pronounced postsynaptic density and an increased synaptic cleft width. These types of synapses also contain prominent presynaptic dense projections as well as subjunctional bodies and may be thus categorized as Gray Type I synapses. However, it must be noted, that when a synapse containing round agranular vesicles makes contact with a soma, there is a less pronounced postsynaptic specialization. Those synapses which contain flattened vesicles, in contradistinction, have symmetrical but poorly defined pre- and postsynaptic densities and do not exhibit presynaptic dense projection or subjunctional bodies. For these reasons, these synapses may be compared to Gray's Type II classification. Principally, the synapses with flattened vesicles are associated with synapses on the soma, axon hillocks, and proximal axon segments of the neuron. The synapses with flattened vesicles may also be associated with more distal dendritic processes, but these are rare.

Use of the electron microscope has allowed some further specification of these synaptic relationships, at least so far as the TCR projection may be analyzed following discrete lesions of the lateral geniculate nucleus (Peters \& Feldman, 1976; Peters, Feldman, \& Saldanha, 1976; Peters \& Saldanha, 1976). Generally, the EM data confirm the earlier autoradiographic analysis indicating termination of TCR axons not only in layer IV, but also, although to a lesser extent, in layer I, the deeper portion of layer III, and layer VI. The axon terminals predominantly contained round vesicles, while the postsynaptic elements of these axon terminals were dendritic spines and shafts, perikarya, and, in one instance, the initial segment of an axon. With the exception of the axoaxonic synapse, all synapses were asymmetrical Gray Type I, although the postsynaptic density was considerably less with respect to synapses on dendritic shafts and somata. Within layer IV, the axon terminals do not indicate any sort of specialized spatial organization, but, rather, occur quite randomly. Eighty-three percent of these layer IV synapses are on dendritic spines, while $15 \%$ are on dendritic shafts and only $2 \%$ are axosomatic. The dendritic spines are most probably associated with apical dendrites of pyramidal neurons of layer $\mathrm{V}$. In some cases, the dendritic spine may be seen in contact with both a degenerating axon terminal and a normal axon, while in other cases a degenerating axon may make contact with more than one postsynaptic element. In either event, the dendritic spine shows no abnormality.

The dendritic shafts receiving TCR axon terminals are quite smooth, with only a very infrequent spinelike protrusion. The shafts are between 0.5 and $2.5 \mu$ and exhibit closely packed microtubules and relatively large mitochondria. Only approximately 1 in 12 of the available synapses show degeneration following lateral geniculate lesions.

Considering the axosomatic synapses, the evidence strongly indicates that the perikarya are the same ones which give rise to the dendritic shafts just previously described. Again, as with the other TCR terminations, the synapses are asymmetric. The somata themselves generally fall into two principally quantitatively distinct classes: large and small. The small variety have a relatively thin ring of cytoplasm surrounding the nucleus and the Golgi apparatus is organized into isolated complexes. Both asymmetric synapses (only some of which exhibit a degenerating presynaptic terminal) and symmetric synapses are present. The large variety, on the other hand, present a more irregular nucleus with a prominent nucleolus. The cytoplasm is more abundant in certain places, suggesting an ovoid cell shape, and the Golgi apparatus more nearly surrounds the nucleus. Additionally, the dendritic processes are more thick and have a tapering base. As with the small variety, both asymmetric and symmetric synapses can be recognized.

Within layer VI, the TCR termination is observed only with EM analysis, and then with some difficulty due to degenerating axons of passage. However, notwithstanding this, the degenerating terminals following lateral geniculate lesions may be observed and, like other TCR terminations, show principally an asymmetrical arrangement. The postsynaptic elements of these asymmetrical synapses are predominantly dendritic spines with only an occasional synapse on a dendritic shaft.

A final point concerning the cellular and synaptic morphology of the rat's striate neocortex involves the possibility that layer $\mathrm{V}$ may be subdivided into two distinct subdivisions similar to what Lorente de No' has suggested as $\mathrm{Va}$ and $\mathrm{Vb}$. The basis for this stems 
from the results of early postnatal bilateral enucleation, which produces a severe decrease in the number of dendritic spines on the apical dendrites of deep layer $\mathrm{V}$ pyramidal cells as these dendrites pass through layer IV. In contradistinction, the apical dendrites of the more superficial layer $\mathrm{V}$ pyramidal cells show no such denudation. Ryugo, Ryugo, and Killackey (1975) also observed that the deep pyramidal cells are somewhat larger than the more superficial pyramidal cells, and thus suggest that superficial cells constitute layer $\mathrm{Va}$ while the deep cells constitute layer Vb. It must be noted, however, that due to the extreme transneuronal degeneration observed within the rat's visual system, these data do not necessarily demonstrate direct synaptic connections between the lateral geniculate nucleus and the layer $\mathrm{V}$ pyramidal cells. And this is so even though, as described above, Peters and his associates reported that degenerating TCR terminals are associated with dendritic spines since, in this case, it is impossible to trace the dendrite back to its origin. However, the possibility that TCR axons synapse directly with the apical dendrites of layer $\mathrm{V}$ pyramidal cells would seem somewhat more likely than a speculative possibility.

\section{CONCLUSION}

The present review was concerned with the primary visual system of the rat. Included in this was consideration of the receptor system, the lateral geniculate nucleus, the superior colliculus, and the visual neocortex. At each of these levels, Polyak's suggestion that the rat's visual system represents a transitional system was given some support. The most salient examples are, of course, the distinct possibility that the retina lacks cones and the barest beginnings of lamination within the dorsal portion of the lateral geniculate. Nonetheless, the rat's visual system is far from simple, and certain aspects of its complexity are just now being fully appreciated, as, for example, retinotopic specificity and neocortical termination of lateral geniculate TCR neurons. Thus, the rat's primary visual system may offer a model of visual anatomy that is, on the one hand, simple enough not to defy comprehension yet, on the other hand, complex enough to be interesting.

Moreover, while the rat is certainly not as visual as the primate, it is just as certainly not visually inept and presents some interesting opportunities for visual research. That is, the rat is a convenient overall size, and this, coupled with a smooth brain and a mostly crossed visual system, lends certain analytical advantages. For example, electrophysiological research is not hampered by brain convolutions which must be accounted for in the interpretation of visual mapping or neocortical organization. Also, the predominantly crossed system, which in certain instances is complete, provides within-subject control and comparisons of anatomical manipulations. These sorts of benefits, with what is already known about the rat's visual system and the rat's behavioral amenability to certain visual tasks, makes the animal a very likely candidate for the investigation of visual structure/function relationships. And this investigation may be more than a simple concession to convenience if the rat's visual system is, in truth, a prelude to that enjoyed by higher mammals.

\section{REFERENCES}

AdAms, A., \& Forrester, J. The projection of the rat's visual field on the cerebral cortex. Quarterly Journal of Experimental Physiology, 1968, 53, 327-336.

Bruesch, S. R., \& AREY, L. B. The number of myelinated and unmyelinated fibers in the optic nerve of vertebrates. Journal of Comparative Neurology, 1942, 77, 631-665.

Bunt, A. H., Lund, R. D., \& Lund, J. S. Retrograde axonal transport of horseradish peroxidase by ganglion cells of the albino rat retina. Brain Research, 1974, 73, 215-228.

CAJAL, S. RAMON Y. Histologie du systéme nerveux de l'homme et des vertèbres (Vol. II) (1911). Madrid: Consejo Superior de Investigaciones Cientificas, 1954.

CunninghaM, T. J., \& Lund, R. D. Laminar patterns in the dorsal division of the LGN of the rat. Brain Research, 1971, 34, 394-398.

De Roberts, E., \& Franchi, C. M. Electron microscopic observations on synaptic vessicles in synapses of the retinal rods and cones. Journal of Biophysical and Biochemical Cytology, 1956, 2, 307-318.

DetwilaR, S. R. Vertebrate photoreceptors. New York: Macmillan, 1943.

Doyt, E., \& Echte, K. Dark and light adaptation in pigmented and white rat as measured by electroretinogram threshold. Journal of Neurophysiology, 1961, 24, 427-445.

DRÄGER, U. C. Autoradiography of tritiated proline and fucose transported transneuronally from the eye to the visual cortex in pigmented and albino mice. Brain Research, 1974, 82, 284-292.

Dubin, M. W. The inner plexiform layer of the vertebrate retina. A quantitative and comparative electron microscope analysis. Journal of Comparative Neurology, 1970, 140, 479-505.

ECCles, J. C., \& JAEger, J. C. The relation between the mode of operation and the dimensions of the junctional regions at synapses and motor-end organs. Proceedings of the Royal Society B, 1958, 148, 38-56.

Forrester, J., \& Peters, A. Nerve fibers in optic nerve of rat. Nature, 1967, 214, 245-247.

Giolli, R. A., \& CREEL, D. J. Inheritance and variability of the organization of the retinogeniculate projections in pigmented and albino rats. Brain Research, 1974, 78, 335-339.

Goodman, D. C., Bogdasarian, R. S., \& Horel, J. A. Axonal sprouting of ipsilateral optic tract following opposite eye removal. Brain, Behavior and Evolution, 1973, 8, 27-50.

Goodman, D. C., \& Horel, J. A. Sprouting of optic tract projections in the brain stem of the rat. Journal of Comparative Neurology, 1966, 127, 71-88.

Graham, C. H., \& Riggs, L. A. The visibility curve of the white rat as determined by the electrical response to lights of different wavelengths. Journal of Genetic Psychology, 1935, 12, 279-295.

GranIT, R. Sensory mechanisms of the retina. New York: Oxford University Press, 1947.

Gray, E. G., \& Pease, H. L. On understanding the organization of the retinal receptor synapses. Brain Research, 1971, 35, 1-15. Graybiel. A. M. Visuo-cerebellar and cerebello-visual connections 
involving the ventral lateral geniculate nucleus. Experimental Brain Research, 1974, 20, 303-306.

Grossman, A.; Lieberman, A. R., \& Webster, K. E. A Golgi study of the rat dorsal lateral geniculate nucleus. Journal of Comparative Neurology, 1973, 150, 441-468.

Hayhow, W. R., Sefton, A., \& Webb, C. Primary optic centers of the rat in relation to the terminal distribution of the crossed and uncrossed optic nerve fibers. Journal of Comparative Neurology, 1962, 118, 295-322.

Hughes, H. C. Anatomical and neurobehavioral investigations concerning the thalamo-cortical organization of the rat's visual system. Journal of Comparative Neurology, 1977, 175, 311-335.

JACOBSON, S. Distribution of commissural axon terminals in the rat neocortex. Experimental Neurology, 1970, 28, 193-205.

KöNIG, J. F. R., \& KLIPPEL, R. A. The rat brain, a stereotaxic atlas of the forebrain and lower parts of the brain stem. Baltimore: Williams and Wilkins, 1963.

KRIEBEL, R. M. Neurons of the dorsal lateral geniculate nucleus of the albino rat. Journal of Comparative Neurology, 1975, 159, 45-68.

Krieg, W. J. S. Connections of the cerebral cortex. I: The albino rat. A: Topography of the cortical area; B: Structure of the cortical area. Journal of Comparative Neurology, 1946, 84, 221-323.

LADMAN, A. J. The fine structure of the rod-bipolar cell synapse in the retina of the albino rat. Journal of Biophysical and Biochemical Cytology, 1958, 4, 459-466.

LANGER, T. P., \& LUND, R. D. The upper layers of the superior colliculus of the rat: A Golgi study. Journal of Comparative Neurology, 1974, 158, 405-436.

LASHLEY, K. S. The mechanism of vision. V: The structure and image forming power of the rat's eye. Journal of Comparative Psychology, 1932, 18, 363-366.

LASHLEY, K. S. The mechanism of vision. VII: The projection of the retina upon the primary optic centers in the rat. Journal of Comparative Neurology, 1934, 59, 341-373.

LEURE-DUPREE, A. E. Observations on the synaptic organization of the retina of the albino rat: A light and electron microscope study. Journal of Comparative Neurology, 1974, 153, 149-178.

LieBerman, A. R. A class of neurons with presynaptic perikarya and dendrites in rat dorsal lateral geniculate nucleus (LGNd). Journal of Anatomy, 1972, 113, 283.

Lieberman, A. R. Neurons with presynaptic perikarya and presynaptic dendrites in the rat lateral geniculate nucleus. Brain Research, 1973, 59, 35-59.

Lieberman, A. R., \& Webster, K. E. Presynaptic dendrites and a distinctive class of synaptic vessicle in the rat dorsal lateral geniculate nucleus. Brain Research, 1972, 42, 196-200.

Lieberman, A. R., \& Webster, K. E. Aspects of the synaptic organization of intrinsic neurons in the dorsal lateral geniculate nucleus: An ultrastructural study of the normal and of the experimentally deafferented nucleus in the rat. Journal of Neurocytology, 1974, 3, 677-710.

LUND, R. D. Terminal distribution in the superior colliculus of fibers originating in the visual cortex. Nature, 1964, 204, 1283-1285.

Lund, R. D. The occipitotectal pathway of the rat. Journal of Anatomy, 1966, 100, 51-62.

Lund, R. D. Synaptic patterns of the superficial layers of the superior colliculus of the rat. Journal of Comparative Neurology, 1969, 135, 179-208.

Lund, R. D. Anatomic studies on the superior colliculus. Investigative Ophthalmology, 1972, 11, 434-441.

Lund, R. D., \& Cunningham, T. J. Aspects of synaptic and laminar organization of the mammalian lateral geniculate body. Investigative Ophthalmology, 1972, 11, 291-301.

Lund, J. S., \& Lund, R. D. The termination of callosal fibers in the paravisual cortex of the rat. Brain Research, 1970, 17, 25-45.

Lund, R. D., Lund, J. S., \& WISE, R. P. The organization of the retinal projection to the dorsal lateral geniculate nucleus in pigmented and albino rats. Journal of Comparative Neurology, 1974, 158, 383-404.

MonTERo, V. M. Evoked responses in the rat's visual cortex to contralateral, ipsilateral, and restricted photic stimulation. Brain Research, 1973, 53, 192-196.

Montero, V., Brugge, J., \& Beitel, R. Relation of the visual field to the lateral geniculate body of albino rat. Journal of Neurophysiology, 1968, 31, 221-236.

Montero, V., \& Guillery, R. W. Degeneration in the dorsal lateral geniculate nucleus of the rat following interruption of the retinal or cortical connections. Journal of Comparative Neurology, 1968, 134, 211-243.

Montero, V. M., Rojas, A., \& Torrealba, F. Retinotopic organization of striate and prestriate visual cortex in the albino rat. Brain Research, 1973, 53, 197-201.

Muenzinger, K. F. Vicarious trial and error at a point of choice. I. A general survey of its relation to learning efficiency. Journal of Genetic Psychology, 1938, 53, 75-86.

Muntz, W. R. A. A behavioral study on photopic and scotopic vision in the hooded rat. Brain Research, 1967, 7, 371-376.

Nauta, W. J. H., \& Bucher, V. Efferent connections of the striate cortex in the albino rat. Journal of Comparative Neurology, 1954, 100, 257-285.

Nauta, W., \& Stratten, J. The primary optic centers of the rat. An experimental study by the "bouton" method. Journal of Anatomy (London), 1947, 81, 127-134.

Noback, C., \& LAEMLe, L. Structural and functional aspects of the visual pathways of primates. In C. Noback \& W. Montagna (Eds.), The primate brain. New York: AppletonCentury-Crofts, 1970.

Peters, A., \& Feldman, M. L. The projection of the lateral geniculate nucleus to area 17 of the rat cerebral cortex. I. General description. Journal of Neurocytology, 1976, 5, 63-84.

Peters, A., Feldman, M., \& Saldanha, J. The projection of the lateral geniculate nucleus to area 17 of the rat cerebral cortex. II. Terminations upon neuronal perikarya and dendritic shafts. Journal of Neurocytology, 1976, 5, 85-107.

Peters, A., \& Saldanha, J. The projection of the lateral geniculate nucleus to area 17 of the rat cerebral cortex. III. Layer VI. Brain Research, 1976, 105, 533-537.

Polyak, S. L. The retina. Chicago: University of Chicago Press, 1941.

Polyak, S. L. The vertebrate visual system. Chicago: University of Chicago Press, 1957.

Rafols, J. A., \& Valverde, F. The structure of the dorsal lateral geniculate nucleus in the mouse. A Golgi and electron microscopic study. Journal of Comparative Neurology, 1973, 150, 303-332.

Ribak, C., \& Peters, A. An autoradiographic study of the projections from the lateral geniculate body of the rat. Brain Research, 1975, 92, 341-368.

Ryugo, R., Ryugo, D. K., \& Killackey, H. P. Differential effect of enucleation on two populations of layer $\mathrm{V}$ pyramidal cells. Brain Research, 1975, 88, 554-559.

Sefton, A. J. The innervation of the lateral geniculate nucleus and anterior colliculus in the rat. Vision Research, 1968, 8, 867-881.

Sefton, A. J., \& Swinburn, M. Electrical activity of the lateral geniculate nucleus and optic tract of the rat. Vision Research, 1964, 4, 315-328.

Siminoff, R., Schwassmann, H. O., \& Kruger, L. An electrophysiological study of the visual projection to the superior colliculus of the rat. Journal of Comparative Neurology, 1966, 127, 435-444.

SJöstrand, F. S. The ultrastructure of the inner segments of the retinal rods of the guinea pig eye as revealed by electron microscopy. Journal of Cellular and Comparative Physiology, 1953, 42, 45-70.

Sosula, K., \& Glow, P. A quantitative ultrastructural study of the inner plexiform layer of the rat retina. Journal of Comparative Neurology, 1970, 140, 439-478.

Sumitomo, I., Ide, K., Iwama, K., \& Arikuni, T. Conduction 
velocity of optic nerve fibers innervating lateral geniculate body and superior colliculus in the rat. Experimental Neurology, 1969, 25, 378-392.

Swanson, L. W., Cowan, W. M., \& Jones, E. G. An autoradiographic study of the efferent connections of the ventral lateral geniculate nucleus in the albino rat and the cat. Journal of Comparative Neurology, 1974, 156, 143-164.

Tsang, Y. C. Visual sensitivity in rats deprived of visual cortex in infancy. Journal of Comparative Psychology, 1937, 24, 255-262.

VALVERDE, $R$. The neuropile in the superficial layers of the superior colliculus of the mouse. A correlated Golgi and electron microscopic study. Zeitschrift für Anatomie und Entwicklungsgeschichte, 1973, 142, 117-147.

Vincent, S. B. The mammalian eye. Journal of Animal Behavior, 1912, 2, 249-255.

WaLls, G. L. The visual cells of the white rat. Journal of Comparative Psychology, 1934, 18, 363.

WAUGH, K. The role of vision in the mental life of the mouse. Journal of Comparative Neurological Psychology, 1910, 20, 549-599.

YERKES, R. M. The dancing mouse. New York: Macmillan, 1907.
Young, R. W. The renewal of photoreceptor cell outer segments. Journal of Cell Biology, 1967, 33, 61-72.

\section{NOTE}

1. Subsequent to the completion of this review, an excellent study of the thalamocortical organization of the hooded rat's visual system has appeared (Hughes, 1977). In general, the reported data are in agreement with the literature presently reviewed, with one extremely important addition. This is that the efferent projection of the LGNd is in no way restricted to the classically defined neocortical area, A-17. Rather, the LGNd apparently projects not only to A-17 but also to A-18a. Although other investigators, notably Ribak and Peters (1975) do not report any such projection in the albino rat, Hughes' observations on the hooded rat are quite convincing, since the projection was confirmed using both autoradiography and retrograde transport of horseradish peroxidase as well as an analysis of retrograde degeneration using cresyl violet following restricted neocortical ablations.

(Received for publication July 25, 1977; accepted December 22, 1977.) 